\title{
A Computational Workbench Environment for Virtual Power Plant Simulation
}

\section{Quarterly Progress Report}

Reporting Period Start Date: January 1, 2004

Reporting Period End Date: March 31, 2004

\begin{abstract}
Mike Bockelie, REI
Dave Swensen, REI

Martin Denison, REI

Zumao Chen, REI

Temi Linjewile, REI

Mike Maguire, REI

Adel Sarofim, REI

Connie Senior, REI

Changguan Yang, REI

Hong-Shig Shim, REI
\end{abstract}

April 28, 2004

DOE Cooperative Agreement No: DE-FC26-00NT41047

Reaction Engineering International

77 West 200 South, Suite 210

Salt Lake City, UT 84101 


\section{Disclaimer}

"This report was prepared as an account of work sponsored by an agency of the United States Government. Neither the United States Government nor any agency thereof, nor any of their employees, makes any warranty, express or implied, or assumes any legal liability or responsibility for the accuracy, completeness, or usefulness of any information, apparatus, product, or process disclosed, or represents that its use would not infringe privately owned rights. Reference herein to any specific commercial product, process, or service by trade name, trademark, manufacturer, or otherwise, does not necessarily constitute or imply its endorsement, recommendation, or favoring by the United States Government or any agency thereof. The views and opinions of authors expressed herein do not necessarily state or reflect those of the United States Government or any agency thereof." 


\begin{abstract}
This is the fourteenth Quarterly Technical Report for DOE Cooperative Agreement No: DEFC26-00NT41047. The goal of the project is to develop and demonstrate a Virtual Engineeringbased framework for simulating the performance of Advanced Power Systems. Within the last quarter, good progress has been made on all aspects of the project.

Software development efforts have focused primarily on completing a prototype detachable user interface for the framework and on integrating Carnegie Mellon Universities IECM model core with the computational engine. In addition to this work, progress has been made on several other development and modeling tasks for the program. These include: 1) improvements to the infrastructure code of the computational engine, 2) enhancements to the model interfacing specifications, 3) additional development to increase the robustness of all framework components, 4) enhanced coupling of the computational and visualization engine components, 5) a series of detailed simulations studying the effects of gasifier inlet conditions on the heat flux to the gasifier injector, and 6) detailed plans for implementing models for mercury capture for both warm and cold gas cleanup have been created.
\end{abstract}




\section{Table of Contents}

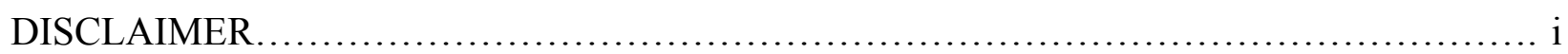

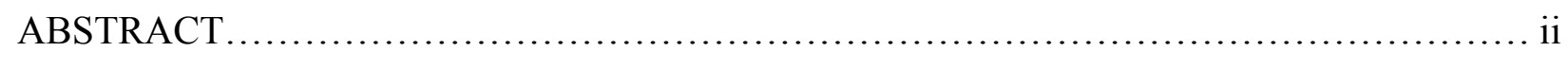

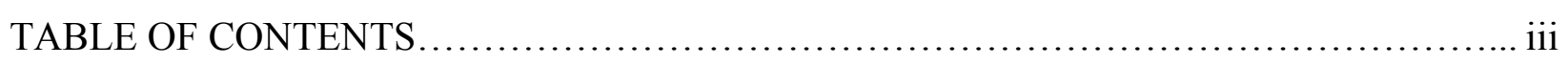

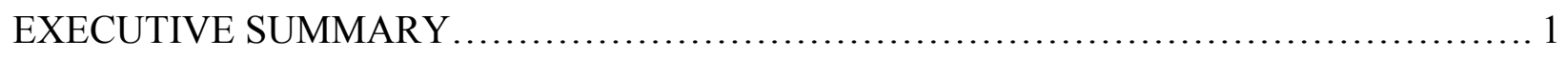

EXPERIMENTAL METHODS...................................................... 2

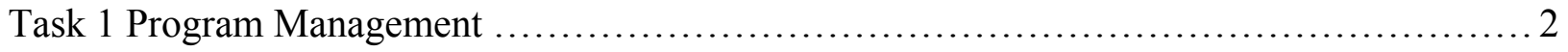

Task 2 Framework Enhancement - Software....................................... 4

Task 3 Framework Enhancement - Modeling... ..................................... 10

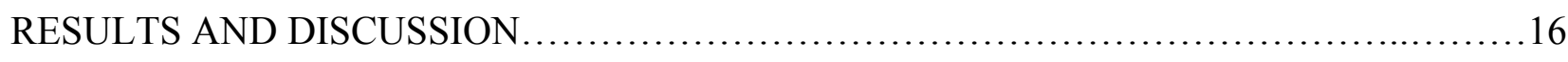

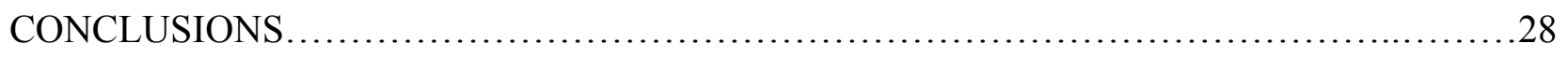

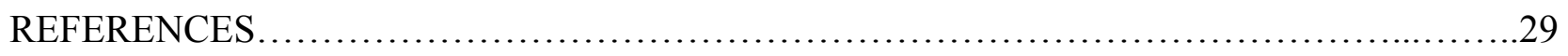

APPENDIX

Absorber and Carbon Bed Design Summaries........................................... 31 


\section{Executive Summary}

The work to be conducted in this project received funding from the Department of Energy under Cooperative Agreement No: DE-FC26-00NT41047. This project period of performance started October 1, 2000. Through a Budget Revision, the project will continue to September 30, 2004.

The goal of the project is to develop and demonstrate a computational workbench, or framework, for simulating the performance of Advanced Power Generation Systems. The Year One effort focused on developing a prototype workbench for the DOE Low-Emissions Boiler System (LEBS) Proof of Concept (POC) design. The Year Two effort focused on developing a more advanced workbench environment for simulating a gasifier-based Vision 21 energyplex. The Year Three effort focused on continued development of the workbench environment and application of the workbench to Vision 21 plant configurations. The Year Four effort, which corresponds to the Budget Revision time period, is incorporating software enhancements to the workbench environment to (a) move it toward a Virtual Engineering based software framework, in which there is available a hierarchy of plant component models that can be connected in a user centered, interactive, immersive, 3D environment and (b) implement improvements to component models for critical plant processes, such as gasification and syngas clean up (including gas separation and mercury capture). This work effort is being closely coordinated with DOE funded projects at Carnegie Mellon University (CMU) and the Iowa State University Virtual Reality Applications Center (ISU) that are also developing simulation tools for use in evaluating Advanced Power Generation Systems.

The main accomplishments during the last three months included:

- Completion of a prototype user interface for the Virtual Engineering based framework.

- Completion of a demonstration simulation which illustrates the coupling of the framework with CMU's IECM, REI's detailed gasifier model and ISU's VESuite. This demonstration will be on display at the $29^{\text {th }}$ International Technical Conference on Coal Utilization \& Fuel Systems in Clearwater Florida.

- Continued software development to create the Virtual Engineering framework, including:

- Improvements to the infrastructure code of the computational engine

- Enhancements to the model interfacing specifications

- Additional development to increase the robustness of all framework components

$\circ$ Enhanced coupling of the computational and visualization engine components

- The coordinated effort between Reaction Engineering International (REI) and DOE funded projects at Carnegie Mellon University (CMU) and the Iowa State University Virtual Reality Applications Center (ISU) has made good progress. The teams continue to communicate regularly and have established productive working relationships.

- A detailed write-up on our approach for mercury removal models for both cold and warm gas cleanup configurations.

- Results from a series of detailed simulations studying the effects of gasifier inlet conditions on the heat flux to the gasifier fuel injector.

Each of these topics is discussed in the following sections. 


\section{Experimental Methods}

Within this section we present brief discussions on the many subtasks that must be addressed in developing the workbench (framework). For simplicity, the discussion items are presented in the order of the tasks as outlined in our Budget Revision.

\section{Task 1 - Program Management}

On Friday, February 5, 2004 project team members met with Dr. Neville Holt (EPRI), an industrial advisor to this project, via a scheduled conference call. The meeting provided us the opportunity to discuss our progress on developing entrained flow gasifier models, gasifier system modifications that would benefit industry that can be modeled with our IGCC framework and possible future needs in gasification research.

On Tuesday, February 17, 2004 REI provided an informal seminar on coal gasification and IGCC basics, issues and opportunities to business development and analyst personnel from the second largest coal company in the USA (company ships more than 100 million tons per year of coal). The coal company has property holdings in Central Appalachia (high sulfur coals) and in the western USA (lignite coals) and thus is interested in different coal gasification technologies. The knowledge base, modeling results and industry contacts developed from this project formed the basis of the seminar content. Motivation for the seminar was a technology update so that they can better evaluate potential opportunities (i.e., requests by technology developers for project participation) in upcoming DOE CCPI solicitations and the DOE Futuregen initiative.

During the last performance period, REI has continued to work closely with collaborators at Carnegie Mellon University (CMU, Program Manager: Prof. Ed Rubin) and the Iowa State University Virtual Reality Applications Center (ISU, Program Manager: Prof. Mark Bryden). The result of the collaboration, or coordinated effort, will be a software framework based on Virtual Engineering concepts in which there is available a hierarchy of plant component models that can be connected in a user-centered, interactive, immersive, 3D environment. The Virtual Engineering based framework will provide the ability to interactively visualize and interrogate Advanced Power Generation plant configurations, including those with $\mathrm{CO} 2$ capture such as Futuregen. A conceptual representation of the capability and development effort for the Virtual Engineering framework is shown in the figure below.

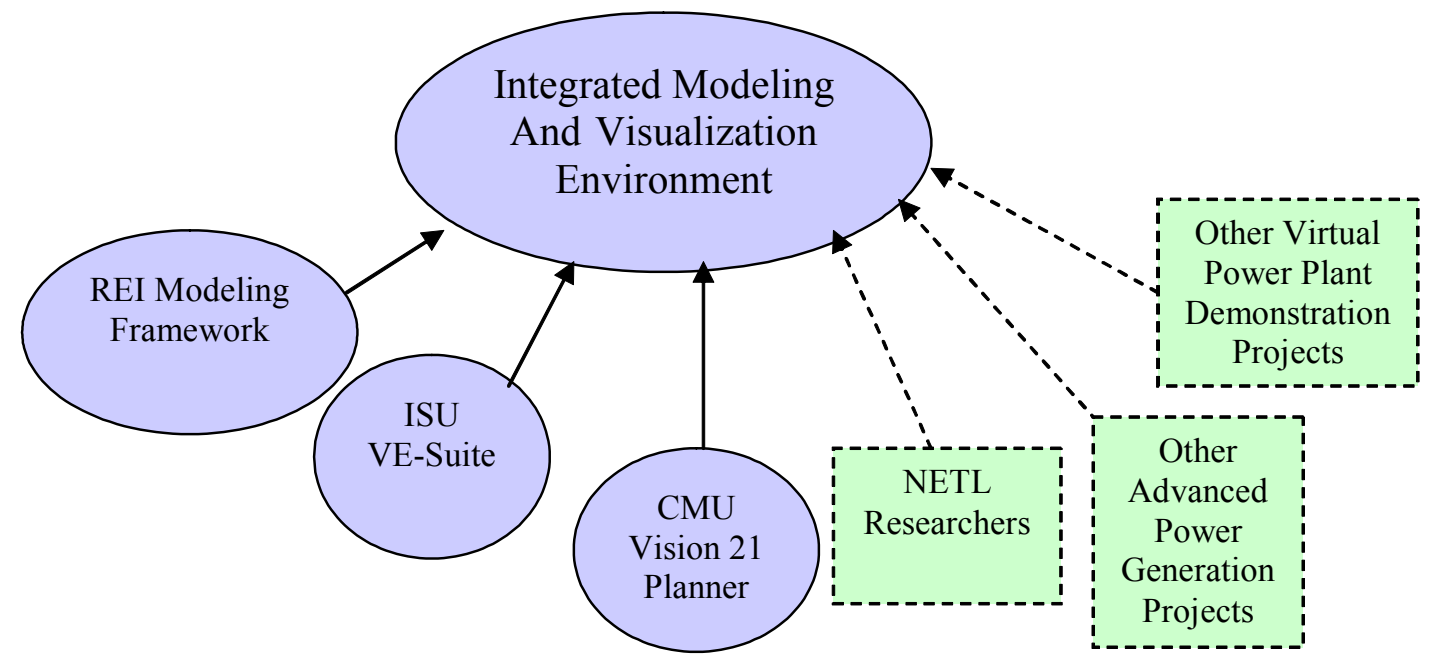


As highlighted in the figure above, REI's role in the CMU-ISU-REI coordinated effort is to incorporate software enhancements to our current simulation framework as well as improvements to component models for key processes needed to simulate emerging concepts for Advanced Power Generation. The CMU team is focused on developing simple models for rapid assessment of the performance and economics of Advanced Power Generation plant configurations, including those with Carbon Management. The ISU team is developing advanced visualization software tools to apply Virtual Engineering principles to power generation systems. The enhanced framework will leverage the work products from these separately funded DOE projects at CMU and ISU. In addition, NETL researchers, NETL funded projects and other projects developing simulation tools for modeling advanced power generation systems will be encouraged to collaborate with our coordinated effort.

- During the last performance period:

- A series of information exchanges were conducted between technical and management level personal from CMU, ISU and REI, relating to model interfacing, software exchange, resource allocation and working together in a coordinated manner. To ensure proper coordination, conference calls that include senior personnel are held on roughly a bi-weekly basis. Conference calls that include technical personnel are held on roughly a weekly basis and email communication occurs as needed. As noted herein, good progress is being made on the coordinated efforts.

- Mr. Doug McCorkle (a graduate student at ISU) visited REI from January 11-17, 2004 to work directly with the REI personnel developing software elements that will need to interact closely with the ISU VE Suite software. The result of this visit was a detailed plan for going forward with the computational-to-visualization engine coupling.

- On February 26, 2004 REI technical staff members traveled to ISU to coordinate development efforts and to test a prototype version of the framework in the immersive visualization facilities at ISU.

- On March 3, 2004 senior personnel from CMU, ISU and REI met at ISU to review progress on the coordinated development efforts, including a full demonstration of the Virtual Engineering capabilities using ISU VR facilities. In addition, the meeting provided an opportunity to discuss the details of the demonstration to be provided at the International Technical Conference on Coal Utilization \& Fuel Systems [http://www.coaltechnologies.com] in Clearwater, Florida, April 19-22, 2004.

- During the next performance period:

- Senior technical and management personnel from CMU, ISU and REI will meet again on April 6, 2004 at ISU to coordinate development efforts and to test an upgraded prototype version of the framework in the immersive visualization facilities at ISU.

- The prototype version of the framework will be demonstrated in a joint presentation by REI, ISU and CMU at the International Technical Conference on Coal Utilization \& Fuel Systems in Clearwater, Florida during the dates of 19-22 April 2004. 


\section{Task 2 - Framework Enhancement - Software}

This task involves the integration of the different capabilities of the simulation tools being used by REI, CMU and ISU to create an integrated modeling and visualization environment. The design of this modeling environment will make it possible to interactively configure, analyze, interrogate and visualize advanced power systems on a wide range of platforms and at different levels of detail.

\section{Overview}

During the last quarter, efforts have been focused primarily on the implementation of the software for the virtual engineering based simulation environment. Particular attention was given to the user interface and to the integration of the decoupled IECM calculation block. Implementation details are given in the following sections.

\section{Software Design and Implementation Details}

Figure 1 shows a high-level schematic of the software design for the framework (repeated from the last quarterly report due to its importance). As seen in this figure, the key elements of the design are the user interface, computational engine, visualization engine, and component models. Note that the various software elements all exist as independent CORBA components with standardized Interface Definition Language (IDL) implementations (denoted with " $\mathrm{C}$ " in a circle). The use of component architecture design techniques has numerous advantages for this application including platform independence, location transparency and reuse of component models.

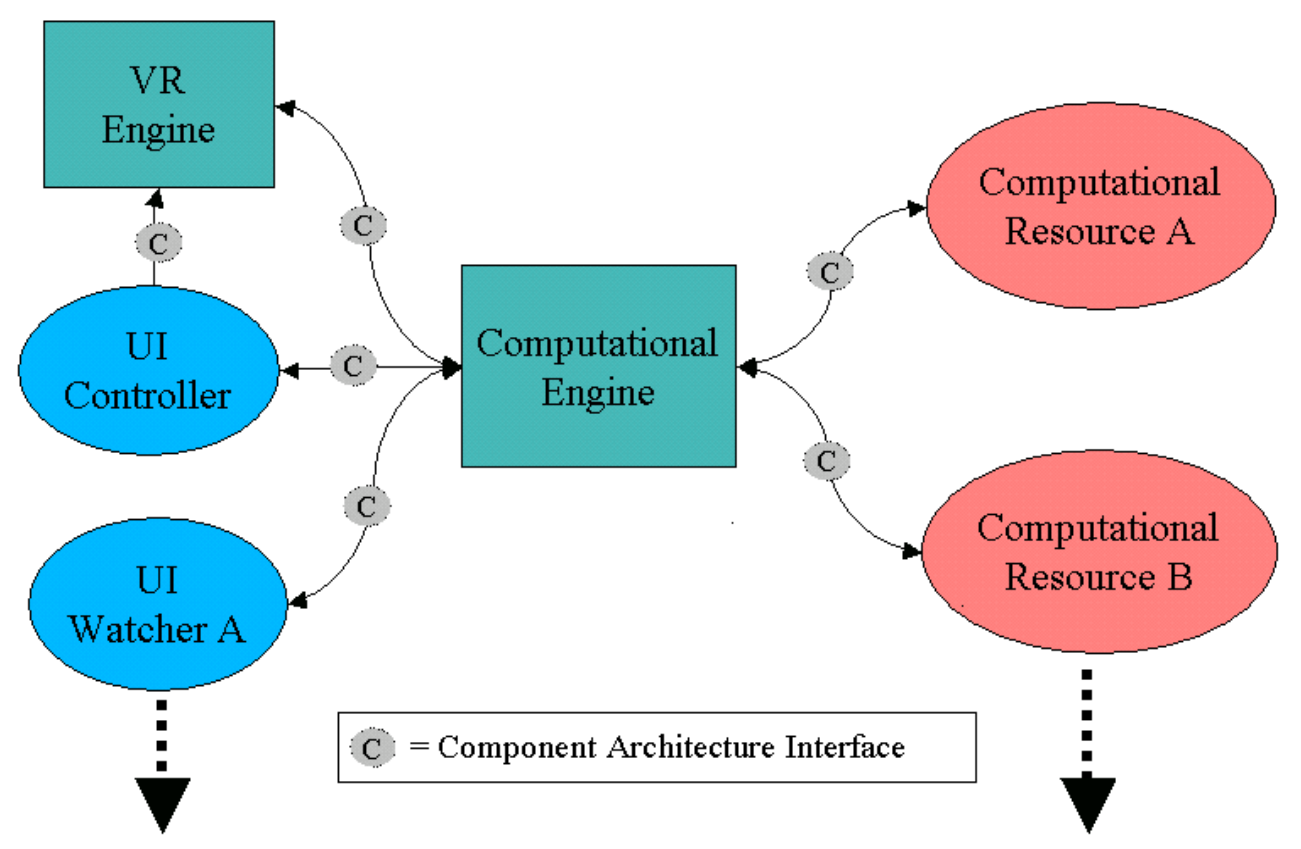

Figure 1. Advanced Power Simulation Framework Design 
The following sections give the current developmental status and implementation details for each of the components of this high-level design.

\section{User Interface}

During the past quarter of work, a prototype user interface (UI) for the framework has been completed.

The prototype UI meets the primary software design goals, which include platform independence, detachability and extensibility.

Multi-Platform support: The UI makes use of platform independent libraries to enable the software to run on a wide range of computer hardware and operating systems. These platforms range from Unix workstations to Windows based PC's, tablets, Pocket PC's and PDA's.

The UI code is based on the wxWidget library [www.wxwidget.org]. This is a powerful multiplatform library that can be run on Windows, Linux, Unix, Mac and other systems. An initial port to Pocket-pc is available now as well. WX provides a wide range of GUI functionality that addresses the needs of this project.

The component architecture library used by the UI is the TAO CORBA package [http://www.cs.wustl.edu/ schmidt/TAO.html]. Again, this library runs on a wide range of platforms.

Detachable/Location Transparency: To accomplish this functionality we use the CORBA component architecture. We have defined a CORBA IDL interface between the UI and the Computational Engine (See Figure 1). This CORBA interface provides all the necessary communication mechanisms between these components. The communication link is bidirectional and handles items such as model parameters passed to the Computational Engine and receives items such as execution status and results from the Computational Engine.

By querying the CORBA naming service, the user interface determines the location of the computational engine and attaches to it. At this point, the user can execute the network, obtain the status of a simulation already running, or view results of a completed simulation. When the user interface goes offline (detached from the computational engine), it continues to allow the user to construct networks and change model input parameters. As a result of these capabilities, the user interface is considered truly detachable.

Extensibility: New models can be added into the simulation framework using a standardized CORBA IDL and standardized user interface templates. The dynamic discover and load capability used by the framework was accomplished by loading user-developed module UI's from dynamic link libraries (DLL in windows) or shared libraries (SO lib in Linux/Unix). This capability was implemented using the wxWidget's RTTI support and shared library support. By using this mechanism, the core framework interface can plug in the third-party, module-specific UI's directly from binaries. 


\section{User Interface Functionality}

Figure 2 shows the main window of the framework UI. As seen in this figure, a list of available modules is displayed in the left pane in a tree structure. A user can create instances of these components on the network construction canvas by simply double clicking. Once the components are placed on the canvas, they are connected with virtual pipes. These pipes designate how information flows between the components. To access the model parameters dialog box for a given component, the user double clicks the component icon. An example of this is shown in Figure 2 for a gasifier model.

Once a network has been constructed and the input parameters changed to desired values, the user attaches to the computational engine, submits the network configuration, and executes the simulation. At this point the user interface is no longer needed for the simulation to continue. It can be detached and reattached later.

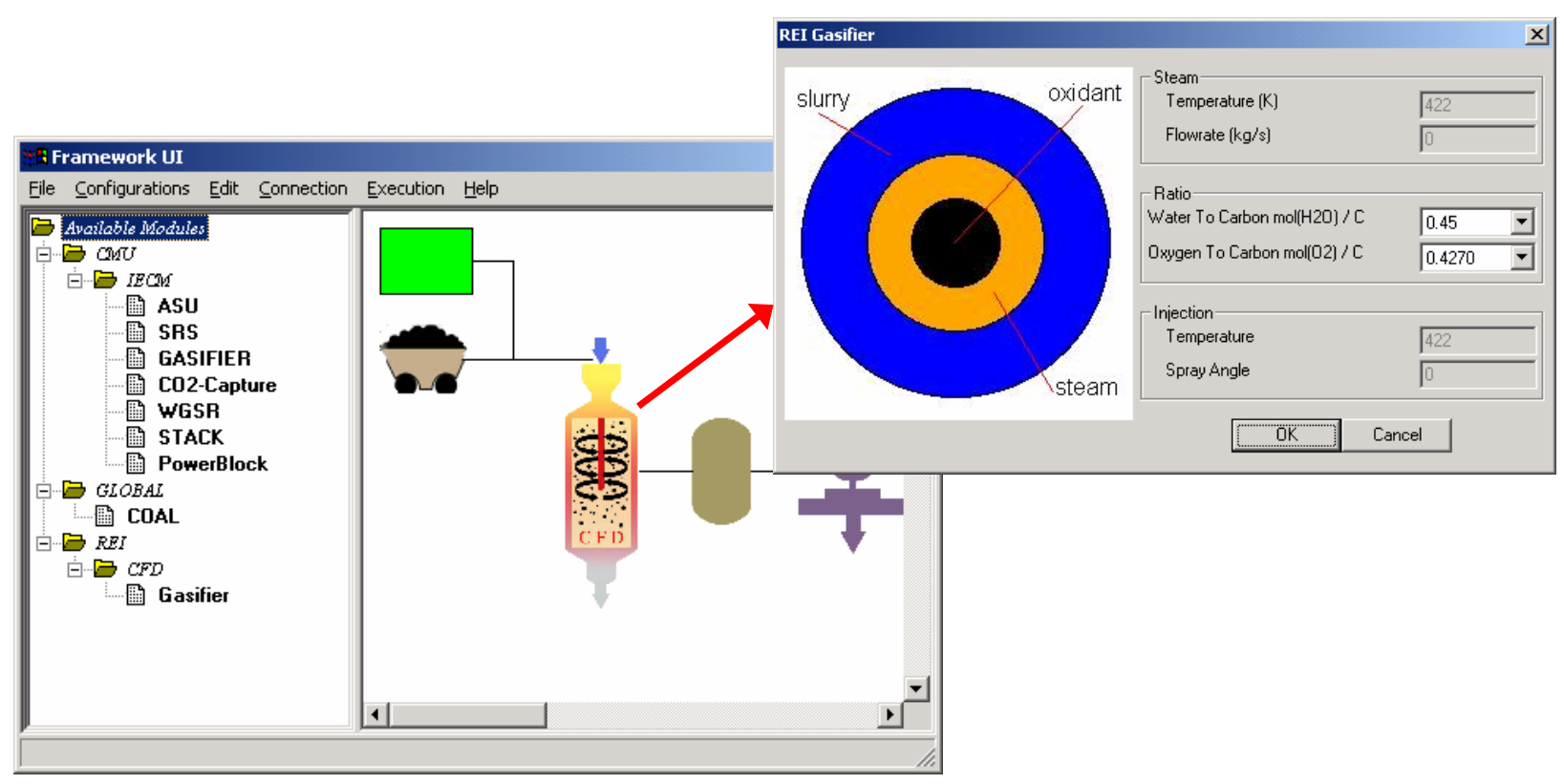

Figure 2. Framework User Interface

The user interface is also used to drive the Virtual Engineering environment. Figure 3 shows these VR UI controls. Through this interface, the user is able to control the elements being displayed in VR space. Available operations include showing and hiding various geometric components and extensive options for showing scalar model data and detailed simulation data. Iowa State University is continuing to update the capabilities of the VR UI as the project continues. 


\section{7}

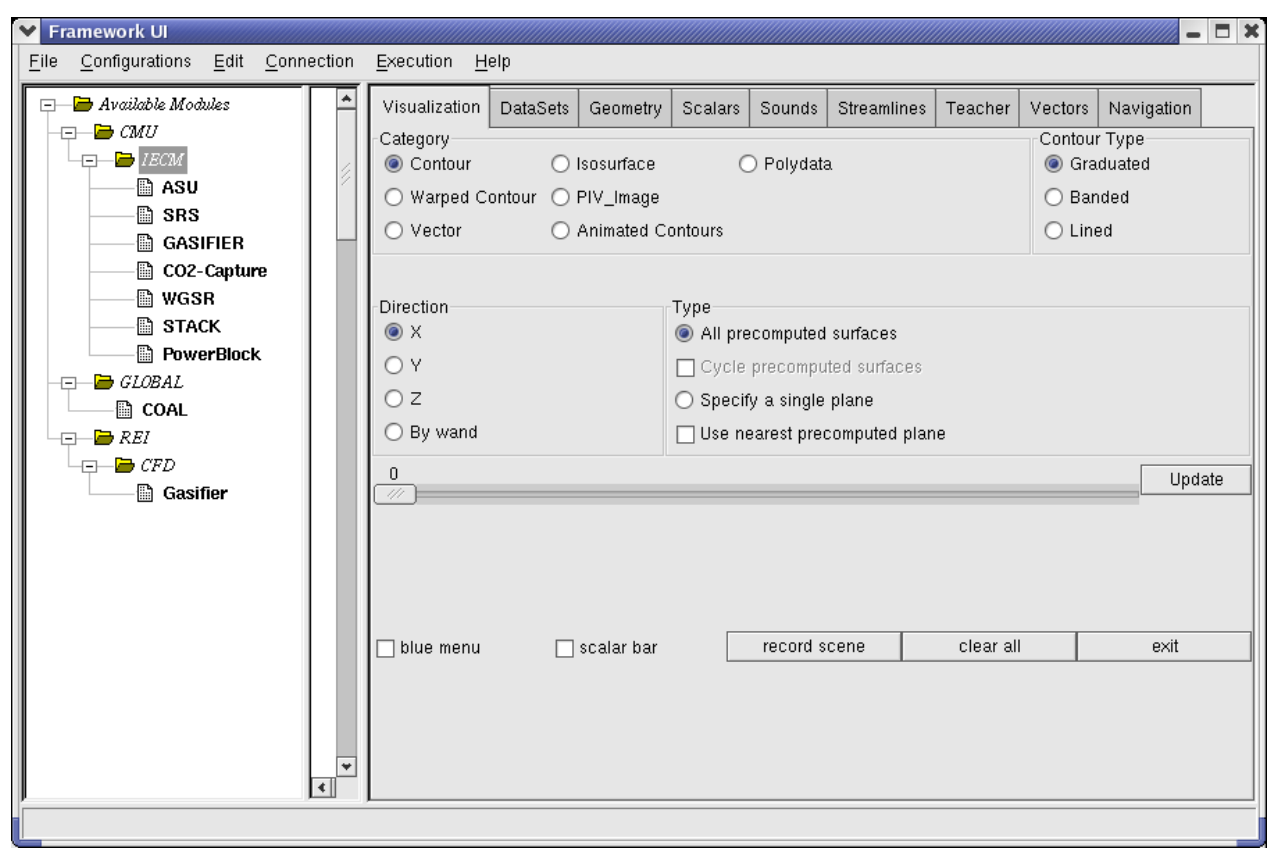

Figure 3. Virtual Engineering User interface

\section{$\underline{\text { Current UI Development Status }}$}

A key task accomplished during the last quarter involved the completion of a prototype user interface for the simulation and visualization framework. This represents the completion of an important milestone for the last quarter.

\section{Computational Engine}

The Computational Engine is the core of the framework. Its duties are to construct, coordinate, schedule, and monitor plant simulations. It must be capable of running a simulation containing a multitude of different types of models, each accepting and generating a myriad of data types. Given the unlimited number of simulation scenarios available for the user to create, the Computational Engine will be focused on a single goal: the successful and accurate plant simulation of a user supplied configuration. To this end, the Computational Engine will be able to analyze a plant configuration, determine execution order, marshal system resources to create model instances, and coordinate the flow of data through the entire simulation framework. Tasks that require specific knowledge about a data type or model are relegated to either a detachable UI or to a specific model, thus keeping the Computational Engine generalized at a high level.

\section{$\underline{\text { Current Computational Engine Development Status }}$}

As an initial step toward creating a flexible computational engine, we have created a controller that drives a CMU IECM core. The controller allows the framework user interface to construct, execute and visualize IECM plant configurations. Although the computational engine interacts with the IECM core via the standardized IDL interface (as per framework design), it does not 
treat each model individually. CMU is currently factoring the IECM core into individual models so that it more closely matches the design required by the framework. We plan to begin integrating the individual IECM components with the framework as they become available during the next quarter.

Using the component interface defined for communication between the computational and visualization engines, we have created the ability for the visualization engine to query the computational engine for key results using a tag designator. These results are then displayed in VR by the visualization engine.

During the next quarter, we plan to continue to enhance the capabilities of the computational engine to support more sophisticated scheduling and data flow. In addition, we plan to begin developing capabilities within the engine to automatically instantiate and access component models on distributed computational resources.

\section{Visualization Engine}

The Visualization Engine provides the core functionality for the virtual engineering aspect of the framework. It is based on VE-Xplorer - a subset of the VE-Suite software developed by Prof. Mark Bryden's research group at ISU.

\section{Current Visualization Engine Development Status}

Over the past quarter, the visualization engine was expanded to allow loading the appropriate graphical components as specified by the computational engine. This functionality allows the user to see the graphical representation of the plant change as the user changes the network on the user interface. This allows the user to, not only create virtual plants, but to walk through them and see them to scale and gain additional knowledge of the plant before a physical plant is constructed.

In addition to creating the interactive geometry component of the visualization engine, functionality was also added to show critical scalar information on virtual gauges and on color mapped connecting pipes. This gives user the ability to track the current status of the plant simulation while in the virtual environment. The gauges and color mapped piping are updated interactively whenever the computational engine calculates simulation results. Navigation in VR space was also integrated into the user interface (see Figure 3) so that the user can interact with the virtual environment completely from a laptop or other compute device. This allows the user to be independent of the hardware running the simulation.

\section{Component Models}

Component models are mathematical representations of individual plant components; the framework, using combinations of these representations, builds an overall simulation. The key to making the simulation framework extensible is to provide a mechanism by which component models can be easily integrated without the need for extensive software development tasks. As 
described in previous reports, we have created the extensibility mechanism using the CORBA component architecture with a standardized interface.

\section{Current Component Model Development Status}

Software engineers from REI and CMU have completed the process of wrapping the core computational model from the CMU IECM Vision21 planner software with the new computational engine. This task is a first step toward full integration of individual models contained within IECM. CMU is beginning work on extracting the component models out of the IECM structure to make it compatible with the new framework. It is expected that this work will be completed during the next quarter.

While the CMU IECM Vision 21 Planner provides a wide range of fast running component models, we are also in the process of porting the range of simple and detailed computational models residing in REI's current Vision21 workbench. Currently, we have completed a rudimentary port of the detailed REI gasifier model to the new framework. Additional Vision 21 workbench models will be ported to the new framework as needed during the next quarter.

In addition to creating framework-compatible REI and CMU models, we are planning to work with other researchers to port their models to the framework. Since the entire framework uses open source and open standard interfaces, other researchers should find it powerful and relatively easy to work with. 


\section{Task 3 - Framework Enhancement - Modeling}

This task involves the enhancement of the models contained within our original IGCC framework. Targeted items are improvements to the gasifier models, a greater range of models for gas clean up and metals (mercury) capture and collaborations for benchmarking reduced order models. All improved models will be integrated into the enhanced framework. In the following we summarize recent efforts and highlight future plans.

\section{MERCURY REMOVAL IN ADVANCED POWER GENERATION IGCC PLANTS}

\section{Introduction}

Mercury has been identified as the air toxic substance of greatest concern among all the air toxics released from coal-fired power plants (Keating, 1997). The EPA has proposed to regulate emissions of mercury from coal- and oil-fired electric utility steam generating units at the level of $19 \mathrm{lb} / 10^{12} \mathrm{Btu}$. Final regulations will be issued by December 15, 2004.

A US DOE study on major environmental aspects of gasification-based power generation technologies (Ratafia-Brown et al, 2002) revealed that approximately 60 to $70 \%$ of the mercury in the coal escaped in the flue gas of the Polk and Wabash River IGCC plants. A separate joint DOE/EPRI/LGTI study, also reported in Ratafia-Brown et al (2002), showed that mercury emissions at the Louisiana Gasification Technology Inc. (LGTI) project accounted for only $31 \%$ of the initial mercury input in the coal. The LGTI Project, sometimes known as the Dow Syngas Project, stopped operations in 1995. Table 1 is a summary of the mercury emission measurements at the three IGCC plants. Inasmuch as most of the mercury released from a gasifier exists as elemental mercury, a gas phase mercury removal technique is recommended.

Table 1. Comparisons of mercury emissions at three IGCC plants.

\begin{tabular}{|l|l|l|l|}
\hline & Polk Plant & Wabash River Plant & LGTI Plant \\
\hline Gasifier Type & ChevronTexaco & E-Gas & E-Gas \\
\hline Plant Net Capacity, MWe & 250 & 262 & 160 \\
\hline Coal Type & Eastern Bituminous & Midwestern Bituminous & Wyoming PRB \\
\hline Mercury Input, lb/Trillion Btu & 8.9 & 6.5 & 5.6 \\
\hline Mercury Input, lb/hr & 0.0207 & 0.016 & 0.015 \\
\hline Mercury Stack Emissions, lb/hr & 0.0121 & 0.0108 & 0.0046 \\
\hline Mercury Emission, \% of input & 58.5 & 67.5 & 30.7 \\
\hline $\begin{array}{l}\text { Mercury Emission Factor, } \\
\text { lb/Trillion Btu }\end{array}$ & 5.2 & 4.4 & 1.7 \\
\hline Source: Ratafin & & \\
\hline
\end{tabular}

Source: Ratafia-Brown et al, 2002.

\section{Mercury Removal in Gasification}

The Fate of Mercury in an IGCC Plant. In order to minimize mercury emissions to the atmosphere, knowledge of its speciation is required. A lot more is known about mercury speciation in coal combustion systems than in gasification systems. In particular, the physical and chemical processes that govern the interactions of mercury with the syngas in gasification 
systems are not well known. However, it is generally agreed that the various mercury species that may be found in gasification streams include elemental mercury $\left(\mathrm{Hg}^{0}\right)$, oxidized mercury $\left(\mathrm{HgO}\right.$ and $\left.\mathrm{HgCl}_{2}\right)$, and mercuric sulfide $(\mathrm{HgS})$. Further, thermodynamic calculations reported in the literature (Galbreath and Zygalicke, 1966) predict that in the reducing conditions of a coal gasifier, elemental mercury is the only stable mercury species. It may be noted, however, that as the flue gas leaves the gasifier and travels through various gas conditioning modules, the gases cool and it is possible for reactions of elemental mercury and flue gases species to occur. In combustion flue gases it is known that elemental mercury can react with $\mathrm{HCl}$ and $\mathrm{Cl}_{2}$ to form $\mathrm{HgCl}_{2}$. Further reactions of $\mathrm{Hg}^{0}$ with $\mathrm{O}_{2}$ can produce $\mathrm{HgO}$. In gasification streams, the fate of mercury as it travels through the various pieces of process equipment is largely unknown. What is generally known is that the mercury remains in the vapor phase, can be adsorbed onto particulates (ash and carbon), and may be removed in liquid scrubbers and acid gas clean-up solvents. From gasifier operating experience, mercury has been found in gasifier slag and ash, in Heat Recovery Steam Generator (HRSG) stack gas, in the Claus sulfur recovery tail gas unit, in acid gas removal amine solvent, in discharge process water, in discharge process solids (scrubber bottoms) and in sulfur and sulfuric acid byproducts. The forms of mercury accumulating in the various process streams is unknown. Recent IGCC plant studies (see Polk Plant and Wabash River Plant in Table 1) show that between 30 and $40 \%$ of the mercury input into these gasifiers is unaccounted for.

Previous Experience. Mercury removal experience from synthesis gas is limited to the Eastman Chemical Company's gasification plant at Kingsport, Tennessee. In this plant, which uses the Texaco gasification technology, syngas is produced for the production of methyl acetate, acetic anhydride and acetic acid (Eastman Chemical Co, 2003). Because of the need for high purity syngas for chemical production, the raw syngas is cooled to $30^{\circ} \mathrm{C}$ and then passed through a bed of sulfur-impregnated activated carbon at 1000 psi for 5 minutes for removal of mercury, prior to being fed to the Rectisol-based Acid Gas Removal plant. The carbon bed removes $90-95 \%$ of the mercury and the adsorbent lasts for 12 to 18 months. It may be noted that industrial-scale mercury removal experience in gas streams originated from the natural gas industry where mercury is removed by activated carbon beds to prevent formation of amalgams, which may lead to equipment failures. Stiegel et al., (2002) report that mercury removal up to $99.99 \%$ from natural gas is achieved using Calgon Carbon's activated carbon type HGR.

Cold Gas Cleanup for Mercury Removal. All gasification processes include an acid gas cleanup plant, regardless of the ultimate use of the syngas produced. Acid gas cleanup steps are usually categorized into cold gas, warm gas and hot gas cleanup depending on the operating temperature range. All commercial acid gas cleanup plants today in operating IGCC units employ the cold gas cleanup strategy. A study by Korens et al. (2002) on alternative processes for gas treating and sulfur removal for gasification contends that efficient and economical removal of mercury from syngas streams will require the use of activated carbon beds and syngas temperatures consistent with cold gas clean-up plants. The suppliers of activated carbon for mercury removal also recommend that to be effective, the carbon beds must be operated at temperatures ranging from $70^{\circ} \mathrm{F}$ to $150^{\circ} \mathrm{F}$.

Location of the Carbon Bed. The temperature requirement for operation of carbon beds makes it necessary to provide the option of a Cold Gas Clean-up Unit (CGCU). Figure 4 is a schematic 
of the Vision 21 plant showing possible locations for a carbon bed for mercury removal. Three likely choices for location of the carbon bed are discussed. In order to operate the activated carbon bed with the existing Warm Gas Clean-up Unit (WGCU) set up, the activated carbon bed must be located downstream of the HRSG. Although locating the carbon bed at this first location would easily meet the temperature requirements for mercury removal, the advantages of operating at high pressure are lost and hence large volumes of gas would have to be processed requiring large vessels and high capital costs. The other two choices involve locating

\section{Vision 21 Flow Sheet with CGCU}

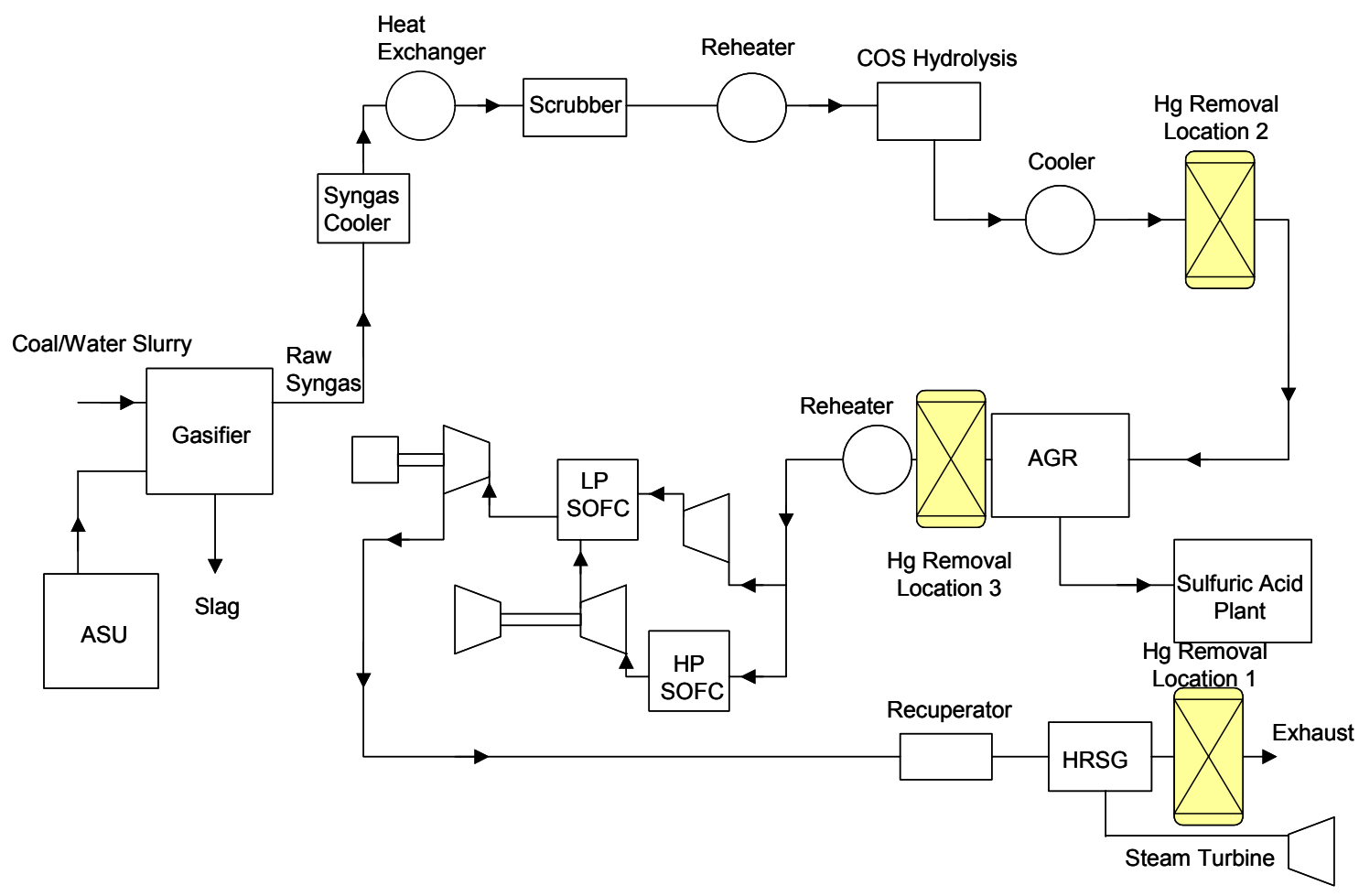

Figure 4. Carbon bed mercury removal options.

the carbon bed in the high-pressure syngas streams. The disadvantage of choosing a carbon bed location in any high-pressure syngas stream is that it will involve cooling the syngas to temperatures in the $100^{\circ} \mathrm{F}$ range. Thus the second choice is to locate the carbon bed before the Acid Gas Removal (AGR) plant. The advantages of locating the carbon bed here are that mercury will be removed before entering the AGR and hence will not contaminate the AGR solvent and the sulfur recovered from it. Further, in gasifier feedstocks made from petroleum residues, metal carbonyls may be present in the syngas stream. Iron $\left(\mathrm{Fe}(\mathrm{CO})_{5}\right)$ and Nickel $\left(\mathrm{Ni}(\mathrm{CO})_{4}\right)$ carbonyls have an impact on downstream turbine blades. However, these impurities can be removed in an activated carbon bed. The third possible choice is to place the carbon bed after the AGR. This location is not desirable since it will allow mercury to accumulate in the AGR solvent. Moreover, according to Burns and Echt (1997) syngas may contain formates, 
which are responsible for formation of heat-stable salts with the AGR solvents. The carbon bed, which would otherwise act as a guard for the AGR against formates, would be ineffective. For the reasons discussed above it is proposed to locate the carbon bed before the AGR.

\section{Carbon Bed Model}

Activated Carbon. Activated carbon, which can have internal surface area of the order of $10^{6}$ $\mathrm{m}^{2} / \mathrm{kg}$ (Coulson et al, 1991), is effective in removing mercury from syngas streams. Calgon Carbon Corporation of Pittsburgh supplies two versions of sulfur-impregnated activated carbons in granular form in 4x10 US Mesh (HGR) and 4mm pellet as HGR-P. These carbons are made from bituminous coals. The sulfur in the carbon reacts with elemental mercury to form a stable mercuric sulfide compound (HgS). Calgon Product Bulletin (1994) states that adsorption systems using the HGR-type activated carbon can be designed to reduce mercury concentrations to below $0.001 \mathrm{ug} / \mathrm{Nm}^{3}$ in the treated gas. The adsorptive capacity of these carbons can be as high as 20 weight percent.

NORIT Americas Inc., of Texas, supplies sulfur-impregnated activated carbon in the form of powder (DARCO FGD) and 3 or $4 \mathrm{~mm}$ pellets (RBHG) made from lignite coal. Both suppliers report that in a properly designed carbon system, the mercury removal process is not affected by inlet mercury concentration or changing the operating pressure. However, increasing the gas temperature or moisture content of the gas stream would drastically affect mercury removal.

Design Approach. Customarily, design calculations of a fixed bed adsorber can be readily made from feed and product gas specifications, equilibrium data, and knowledge of the bed saturation at the beak point under the desired operating conditions. A theoretical basis for design of fixed bed adsorbers is given by Brown et al., (1955), McCabe et al., (1985) and Coulson et al., (1991). However, for adsorption with chemical reaction, the interrelation of these variables is so complex that methods of design usually rely heavily on experimental and operating data of existing plants. The purpose of an adsorber design is to determine the dimensions of the vessel and the quantity of activated carbon required to achieve a specified mercury removal rate. In the simplest of the design approach, the following steps are followed:

- Determination of allowable pressure drop

- Determination of the minimum fluidization velocity

- Determination of allowable superficial velocity through the bed

- Specification of residence time

- Determination of adsorber dimensions

- Calculation of quantity of carbon needed

- Specification of mercury content of coal

- Specify adsorbent lifetime

- Calculate mercury loading of the carbon bed

An example showing details of the calculations for a syngas stream before it enters the mercury removal carbon bed is given in the Appendix. 


\section{Acid Gas Removal Model}

Acid gas removal solvents fall into two broad categories: physical and chemical solvents. The choice of solvent is usually dictated by the $\mathrm{H}_{2} \mathrm{~S} / \mathrm{CO}_{2}$ ratio in the syngas, the solvent's selectivity for $\mathrm{H}_{2} \mathrm{~S}$ over $\mathrm{CO}_{2}$, carbonyl sulfide removal, and whether total removal of $\mathrm{CO}_{2}$ is desired. Physical solvents rely upon variations in the physical solubility of gases to effect separation. Examples are Selexol and Rectisol. Chemical solvents are usually amine-based and remove $\mathrm{H}_{2} \mathrm{~S}$ and $\mathrm{CO}_{2}$ through an acid-base reaction path. One of four amine-based solvents is usually employed (MEA, DGA, TEA and MDEA). In IGCC, selectivity of $\mathrm{H}_{2} \mathrm{~S}$ over $\mathrm{CO}_{2}$ is important. Thus the best chemical solvent for this task is MDEA (Methyldiethanolamine). MDEA actually reacts with $\mathrm{H}_{2} \mathrm{~S}$ but only as a catalyst for hydrolysis of $\mathrm{CO}_{2}$ (Kohl and Nielsen, 1997). MDEA has the lowest capital cost in comparison with Selexol and Rectisol, which may also be selected for IGCC service. Rectisol is the costliest solvent but may be the best choice if complete removal of $\mathrm{CO}_{2}$ is preferred. In this example MDEA is selected.

The proposed process flow diagram for CGCU with $\mathrm{Hg}$ removal is shown in Figure 5. Briefly, raw syngas leaves the gasifier, after which it flows through a syngas cooler. After the syngas cooler, the gas is cooled further in heat exchangers to $400^{\circ} \mathrm{F}$ before entering the water scrubber where $\mathrm{HCN}, \mathrm{NH}_{3}$, chlorides and particulates are removed. After leaving the scrubber at a temperature of $250^{\circ} \mathrm{F}$, the syngas is heated to the temperature of the COS hydrolysis reactor $\left(400^{\circ} \mathrm{F}\right)$. COS is hydrolyzed with steam over a titania or alumina-based catalyst where most of the COS is converted to $\mathrm{H}_{2} \mathrm{~S}$, which is readily removed in the AGR unit. After the COS hydrolysis reactor, syngas is cooled to $100^{\circ} \mathrm{F}$ for mercury removal in the carbon bed. Mercuryfree syngas is then passed through the AGR unit after which the clean syngas is reheated to meet the fuel cell entrance conditions as in the original Vision 21 flowsheet with a hot gas clean-up unit (HGCU). The syngas leaving the AGR unit is specified to meet the $1 \mathrm{ppm} \mathrm{H}_{2} \mathrm{~S}$ limit required for solid oxide fuel cell application. 


\section{Vision 21 Flow Sheet with CGCU}

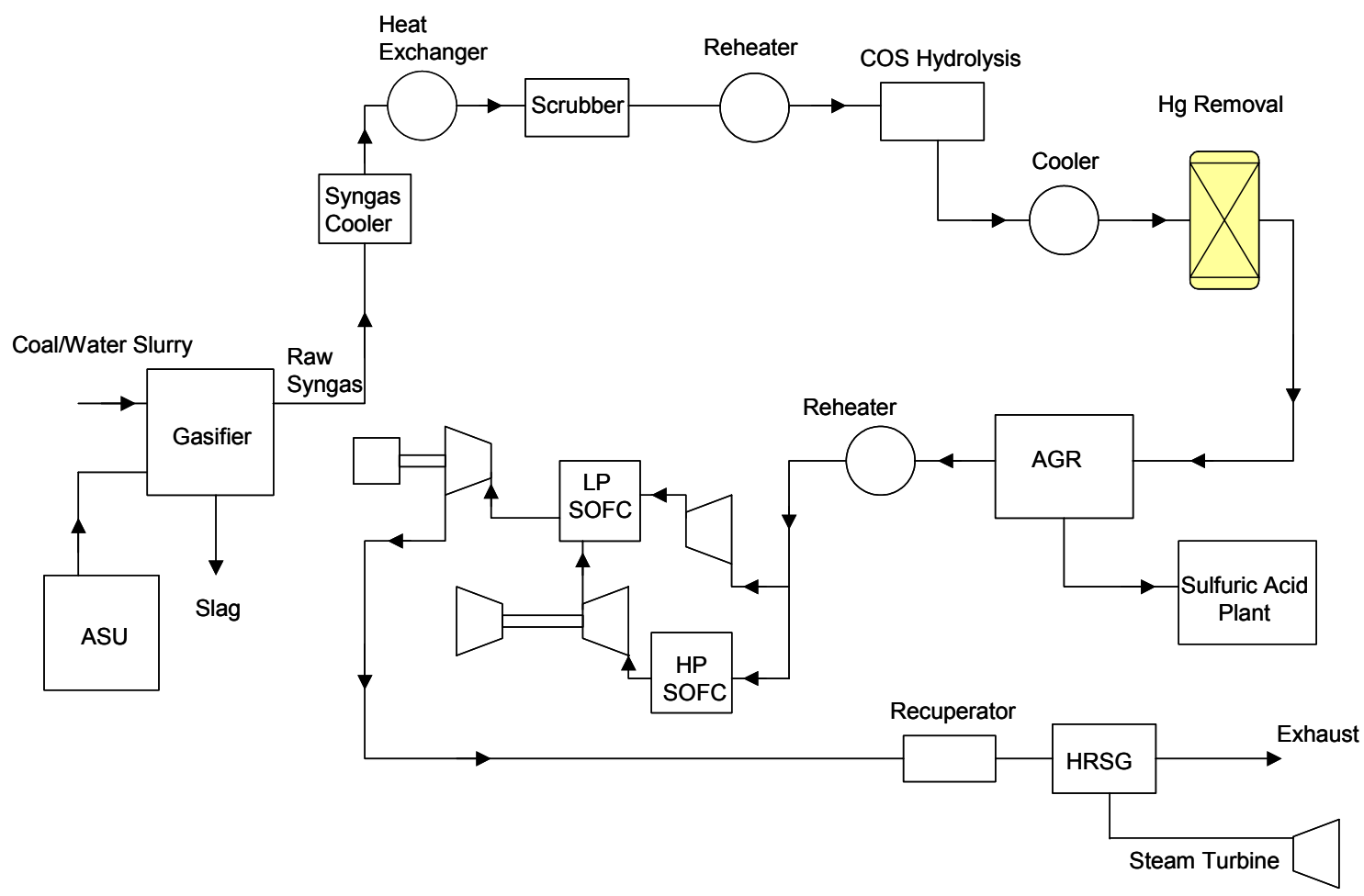

Figure 5. Proposed Vision 21 flow sheet with CGCU for Hg removal. Carbon bed located before the AGR.

The purpose of modeling the AGR unit is to provide information on amine circulation rate required to meet the $\mathrm{H}_{2} \mathrm{~S}$ removal levels, and to determine the size of the absorption tower and the number of stages required to effect the removal of $\mathrm{H}_{2} \mathrm{~S}$. The following steps have been followed; the details of an example of the calculations for a syngas stream before it enters the absorber is given in the Appendix.

- Determination of amine circulation rate

- Determination of active absorber tray area

- Determination of absorber tray diameter

- Determination of liquid residence time

- Determination of theoretical number of stages

- Determination of actual number of trays

- Determination of absorption tower height 


\section{Results and Discussion}

\section{Gasifier Simulations}

An injector is necessary for a gasifier to provide proper atomization of coal-water slurry and intimate mixing with oxidant streams. Typically, an injector consists of a central cylindrical conduit and two to three concentric annular conduits radially spaced to provide coaxial concentric annular passages for different feed streams (Marion et al., 1972; Gettert et al., 1978; Stellaccio, 1984; Saxon, 1985; Lipp, 1987). A water-cooled annular ring is usually provided for cooling the tip of the injector. A typical injector is schematically shown in Figure 6. Note that the central nozzle of the injector may be retracted upstream from the injector face to avoid high heat flux to the injector.

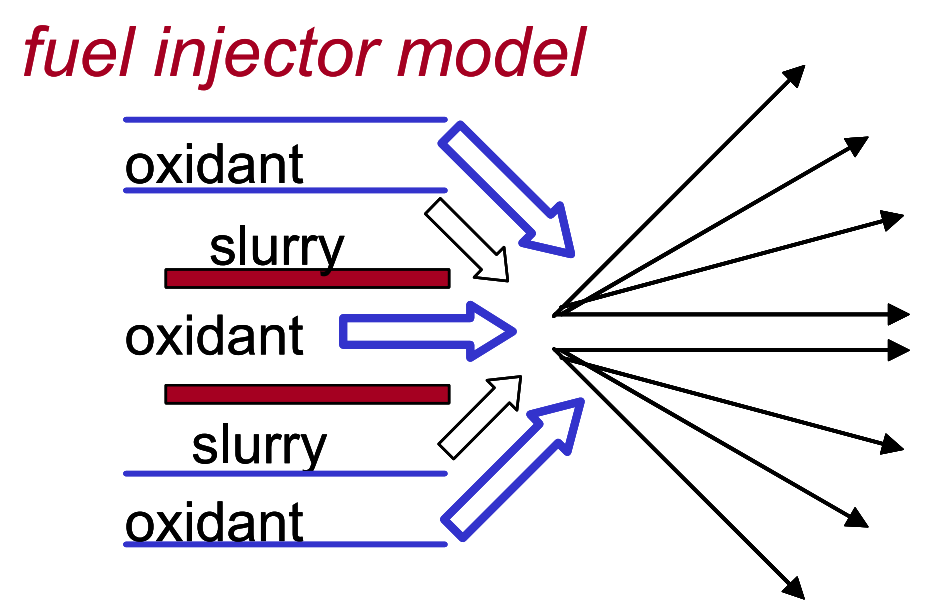

Figure 6: Schematic of a gasifier injector

The life of a typical feed injector nozzle in a gasifier is generally between two and six months. Premature failure of the feed injector limits the gasifier run time and contributes a major fraction of the maintenance cost to the economics of operating a gasification facility. Most often, the failure for the injector is due to high temperature sulfur corrosion and thermal-mechanical fatigue which opens cracks into the cooling water channel on the face, cracks in the coil to face welds. Syngas in the gasifier can then invade the cooling water system, leading to plant shutdown for safety reasons. Thus, the life of the feed injector is vital in the reliability of gasification systems. In order to extend the life of the feed injector, it is important to understand all of the factors affecting injector life and the fluid dynamics near the nozzle. Besides the materials used in the manufacture of the injectors and the feed system (dry feed or slurry feed) used in the gasifier, CFD modeling is useful in understanding issues such as changes in heat flux to the injector.

During the past quarter, CFD simulations using REI's entrained flow gasifier model have been performed to examine the effects of gasifier inlet conditions, such as oxygen distribution between inner injector nozzle and outer injector ring, injector geometry, on the heat flux to the 


\section{7}

injector; the influence of these changes on the performance of the gasifier and the overall power plant efficiency has also been investigated. The operating conditions used in the simulations are the same as those employed in the Tampa Electric Plant (Tampa, 2000) and are summarized in Table 2. Oxidant stream is $95 \%$ pure oxygen. Slurry water was not provided in the Tampa Electric project report and was estimated based on the gasifier exit temperature. Detailed comparison of the CFD model predictions with field data was reported in the last quarterly report. Overall, our CFD model predictions are in good agreement with the data found in the literature. In the simulations reported here, the central nozzle of the injector is located about 1.5 times the diameter of the injector face above the injector face; Figure 7 shows the injector along with the slurry mass fraction profile in the gasifier near the injector, which indicates how the slurry mixes with the oxidant stream. Due to higher momentum of the slurry stream, it is very difficult for the oxidant stream to penetrate into the slurry stream despite a very high velocity of the oxidant stream. This is clearly illustrated in Figure 7: the slurry is discharged from the annular conduit and does not mix immediately with the oxidant from the outer annular passage. Simulations have been performed to evaluate the effect of oxidant distribution between the central nozzle and the outer ring (nozzle), and results are tabulated in Table 3. It can be seen that the gasifier exit temperature decreases and the cold-gas efficiency increases as the oxidant to the outer annular conduit decreases. This is due to the poor mixing between the slurry stream and the oxidant from the outer ring. More oxygen to the inner central nozzle suggests better mixing between slurry and oxidant, hence higher carbon burnout and higher cold-gas efficiency. For the case with 5\% oxidant to the outer nozzle, the gasifier exit temperature is slightly higher than the case with $30 \%$ oxidant to the outer nozzle since the high gas velocity in the central oxidant nozzle leads to a much longer flame as shown Figure 8. Also reported in Table 3 are the net plant power output and the overall plant efficiency calculated using the workbench developed in this project. The net plant power and plant efficiency are directly proportional to the cold-gas efficiency. Not surprisingly, both quantities increase as the oxidant to the outer ring decreases.

Table 2: Operating conditions

\begin{tabular}{|l|c|}
\hline Gasifier pressure, psia & 400 \\
\hline Coal & Pittsburgh \#8 \\
\hline Coal flow rate, tons/day & 2200 \\
\hline Oxidant, tons/day & 2171 \\
\hline Slurry water*, tons/day & 1211 \\
\hline
\end{tabular}

* estimate 


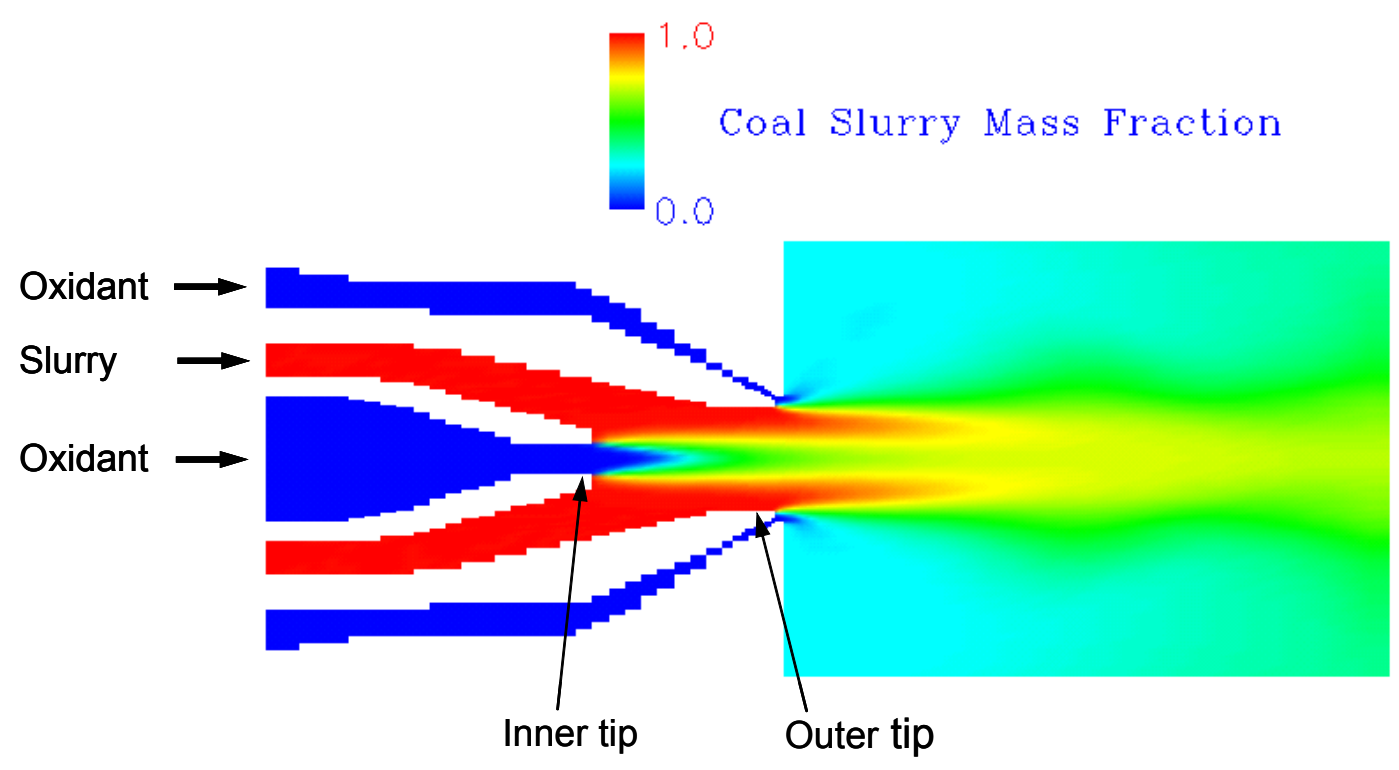

Figure 7: Injector used in the simulations (only portion of the gasifier is shown)

Table 3: Summary of results: effect of oxygen distribution

\begin{tabular}{|r|c|c|c|c|c|}
\hline Outer Nozzle Oxidant, \% & $\mathbf{8 5}$ & $\mathbf{7 5}$ & $\mathbf{5 0}$ & $\mathbf{3 0}$ & $\mathbf{5}$ \\
\hline Exit Temperature, K & 1882 & 1680 & 1627 & 1609 & 1621 \\
\hline Carbon Conversion, \% & 81.1 & 92.4 & 95.9 & 96.3 & 96.7 \\
\hline Exit LOl, \% & 67.7 & 46.1 & 31.8 & 29.3 & 28.1 \\
\hline PFR Residence Time, s & 2.063 & 1.412 & 1.490 & 1.532 & 1.573 \\
\hline Particle Residence Time, s & 0.184 & 0.114 & 0.076 & 0.077 & 0.099 \\
\hline Mole Fraction: CO & 0.3288 & 0.3884 & 0.4012 & 0.4018 & 0.4034 \\
\hline $\mathrm{H}_{2}$ & 0.1978 & 0.2488 & 0.2632 & 0.2658 & 0.2665 \\
\hline $\mathrm{H}_{2} \mathrm{O}$ & 0.2965 & 0.2276 & 0.2076 & 0.2043 & 0.2029 \\
\hline $\mathrm{CO}_{2}$ & 0.1468 & 0.1108 & 0.1038 & 0.1039 & 0.1029 \\
\hline $\mathrm{CH}_{4}$ & 0.002919 & 0.000257 & 0.000190 & 0.000226 & 0.000389 \\
\hline $\mathrm{H}_{2} \mathrm{~S}$ & 0.0049 & 0.0061 & 0.0062 & 0.0062 & 0.0062 \\
\hline $\mathrm{COS}$ & 0.0003 & 0.0003 & 0.0003 & 0.0003 & 0.0003 \\
\hline $\mathrm{N}_{2}$ & 0.0190 & 0.0177 & 0.0174 & 0.0174 & 0.0173 \\
\hline Exit Mass Flow, klb/hr & 415.7 & 437.9 & 443.9 & 444.7 & 444.3 \\
\hline LHV of Syngas, Btu/lb & 2819.3 & 3506.5 & 3701.7 & 3725.1 & 3744.6 \\
\hline HHV of Syngas, Btu/lb & 3249.1 & 3940.1 & 4136.3 & 4159.8 & 4179.4 \\
\hline HHV of Syngas, Btu/SCF & 190.6 & 211.8 & 221.2 & 220.3 & 221.0 \\
\hline Cold-Gas Efficiency, \% & 55.4 & 70.8 & 75.3 & 75.9 & 76.2 \\
\hline Net Plant Power, MW & 209 & 297 & 319 & 321 & 324 \\
\hline Plant Efficiency (HHV, \% & 29.3 & 41.6 & 44.7 & 45.0 & 45.4 \\
\hline
\end{tabular}


Heat flux to the tips of the injector and to the top surface of the gasifier is shown in Figure 9 as a function of the oxidant percentage to the outer nozzle of the injector. Heat flux to the outer and inner tips of the injector increases first and then decreases as oxidant to the outer nozzle increases. Heat flux to the top surface of the gasifier does not change significantly when the oxidant to the outer nozzle is less than $60 \%$. These results indicate that, at a very high percentage of oxidant to the outer nozzle, heat fluxes to the injector tips and to the gasifier top surface are minima. However, the results shown in Table 3 suggest, under these conditions, the cold-gas efficiency is lower and carbon burnout is smaller. It appears that the optimal operating conditions are in the range of $40 \%$ to $60 \%$ oxidant to the outer injector nozzle, in which heat fluxes to the injector tips and to the gasifier top surface are medium while the cold-gas efficiency is around $75 \%$ and carbon burnout is above $95 \%$.

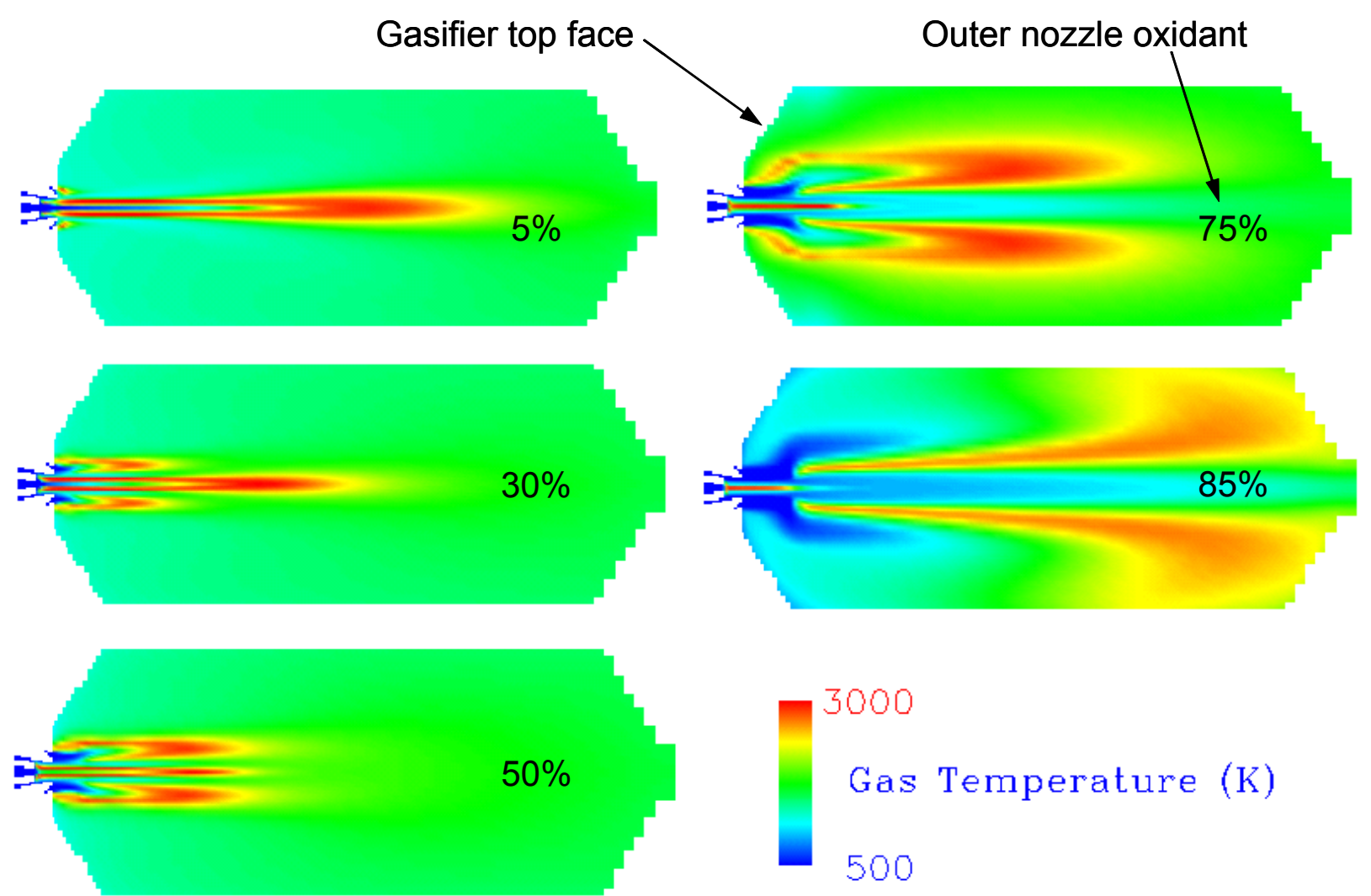

Figure 8: Gas temperature profile: Effect of oxygen distribution 


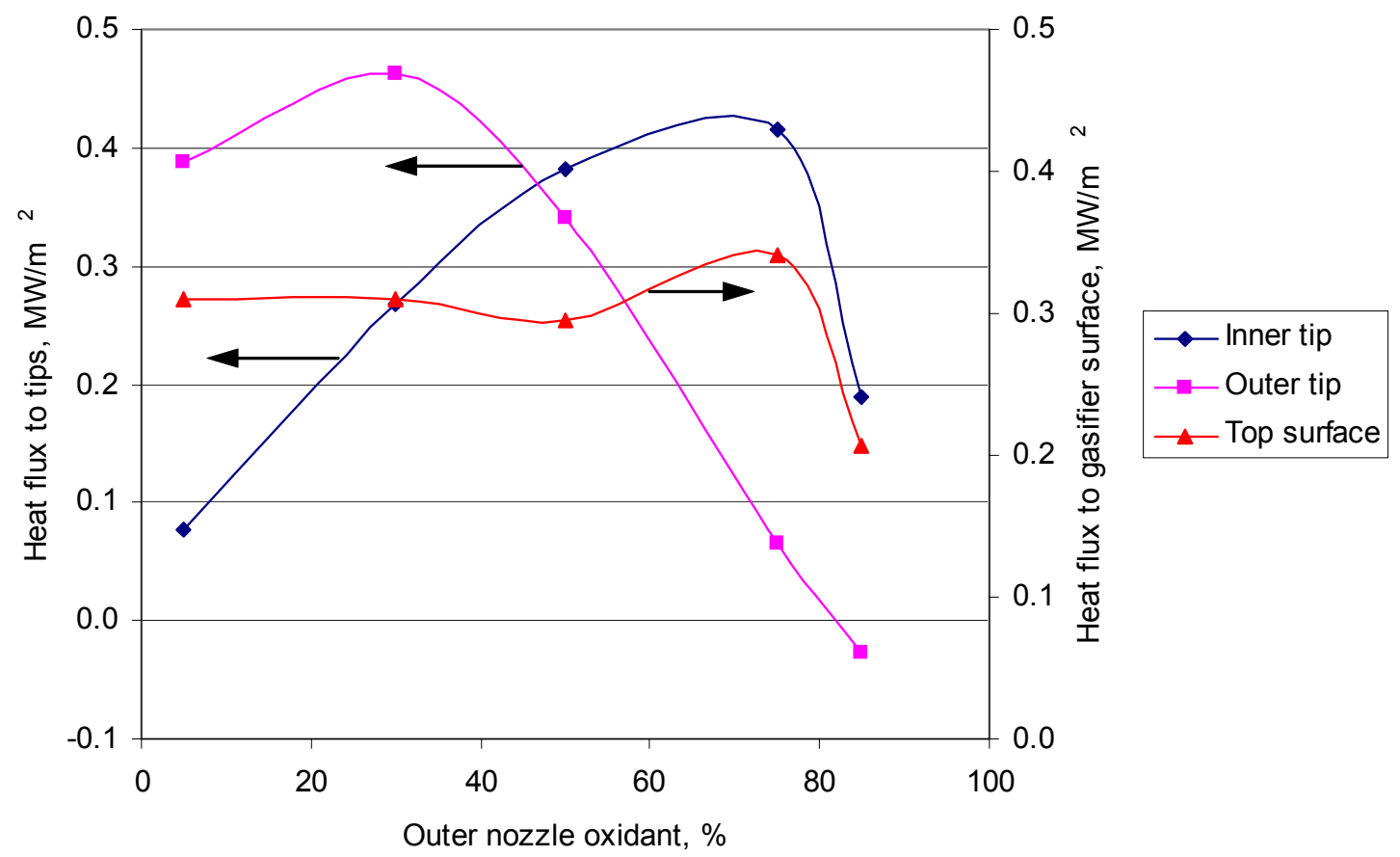

Figure 9: Heat flux as a function of oxidant to the outer nozzle 


\section{Demonstration of Prototype Framework}

With the development efforts of the team during the past quarter, a prototype computational framework is now available for testing and preliminary plant analysis. To showcase the progress being made, a demonstration will be performed at the International Technical Conference on Coal Utilization \& Fuel Systems in Clearwater, Florida in April. This conference is an opportune forum to demonstrate the functionality of the framework, to generate interest, and to receive feedback.

For this demonstration, CMU's IECM suite of models will be used to simulate a typical IGCC plant. Hierarchical model support and plug-and-play capabilities will be demonstrated by replacing the IECM gasifier with REI's detailed model. The demonstration will be run across multiple operating environments and platforms (computational engine and CMU unit model on a Linux workstation, the visualization engine on another Linux workstation and the user interface on a Windows laptop).

The Virtual Engineering space, in addition to the progress noted previously (section XX.XX), has been enhanced to create a tighter coupling to the integrated IECM model by: 1) dynamically altering it's appearance to accurately reflect the configuration chosen by the user, 2) adding 3D gauges to display important plant results/parameters, and 3) adding color mapping of plant components based on data values obtained from model results. Figures showing the Virtual Engineering space can be found in the following sections.

The demonstration will allow full interaction within the framework. The user will be able to configure, run, and view results for the plant design of their choice, limited only by the capabilities of the models themselves. The VE space will be attached to the computational engine for displaying results and creating a "virtual environment" to reflect the current plant configuration.

The following is a script demonstrating key features of the framework to be used for the upcoming Clearwater Conference demonstration. The script and the corresponding figures illustrate how a user interacts with the framework, and the types of visual feedbacks provided to show model results.

1) Initiate the computational engine - the engine is now open via its interfaces and can receive network configurations and data.

2) Initiate a CMU Unit model - upon instantiation, the CMU model registers itself with the engine and waits (also via it's interface) for data and instructions.

3) Initiate the user interface - the UI begins with a "blank slate" (Figure 10), completely isolated and autonomous from the computational engine and attached models.

4) Attach the UI to the computational engine (Figure 11) - the UI registers itself with the engine, creating a communication path to create and control a plant simulation.

5) Load desired pre-configured network (Figure 12) - available configurations correspond to those available under IECM, and are reflected in the VR space (Figure 13).

6) Adjust component model values (Figure 14), and submit network to computational engine (Figure 11) - the network (models and connections) and model inputs are passed 
to the computational engine for storage. The computational engine will use this information for scheduling, resource allocation and error checking.

7) Execute the network (Figure 11) - the UI signals the computation engine to commence network execution.

8) Examine results - the user can view plant results (Figure 15) and port results (Figure 16) in both the VR space and the detachable UI environment.

9) Demonstrate model plug-n-play capabilities by replacing IECM gasifier model with CFD gasifier model - the configuration change is reflected in the VE space (Figure 17).

10) Re-submit and execute the network - this injects CFD results into the simulation network.

11) Examine results - in addition to the visualization options described in $\# 8$, the user can now use the VE Suite interface to examine detailed CFD results directly in the VR space (Figure 18).

12) Detach the UI from the computational engine (Figure 11) - the engine continues to exist independently from the UI. The UI can be reattached at any point to continue running simulations.

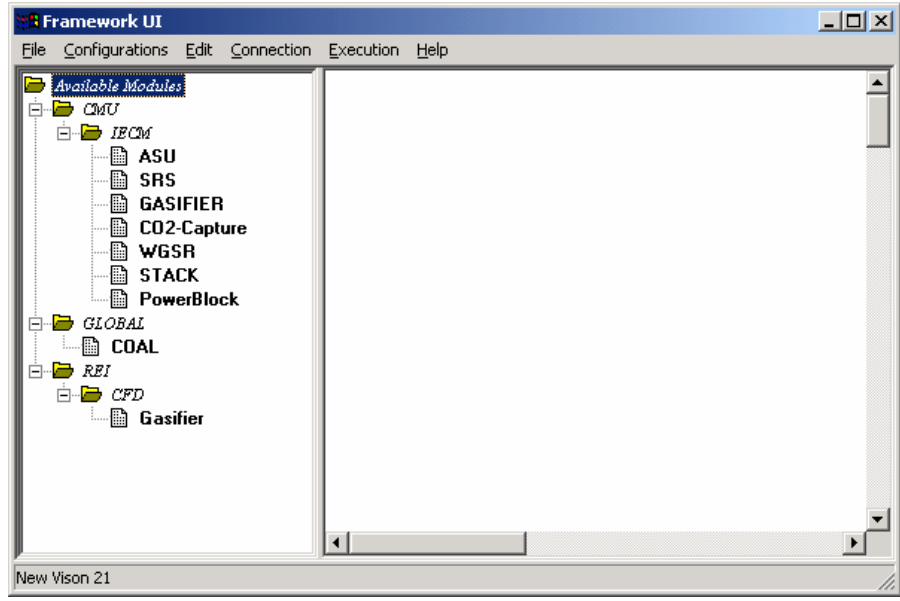

Figure 10. Framework UI
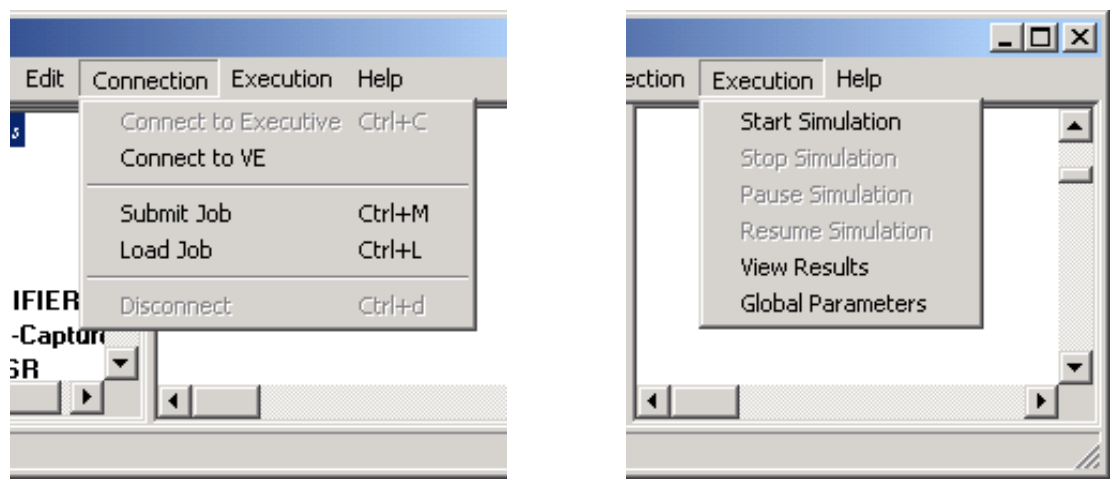

Figure 11. Framework UI connection and execution pull down menus. 

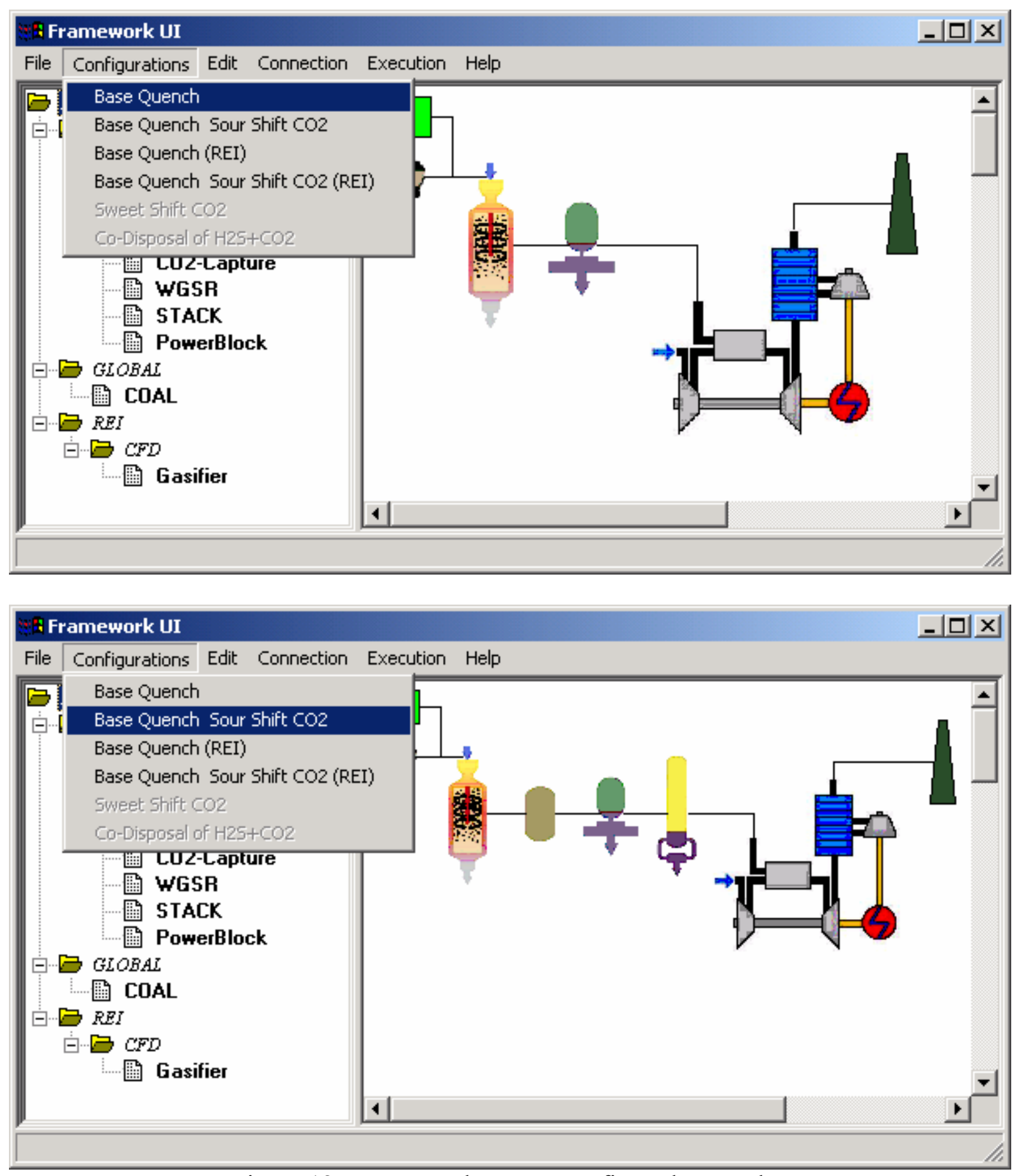

Figure 12. Framework UI pre-configured networks. 


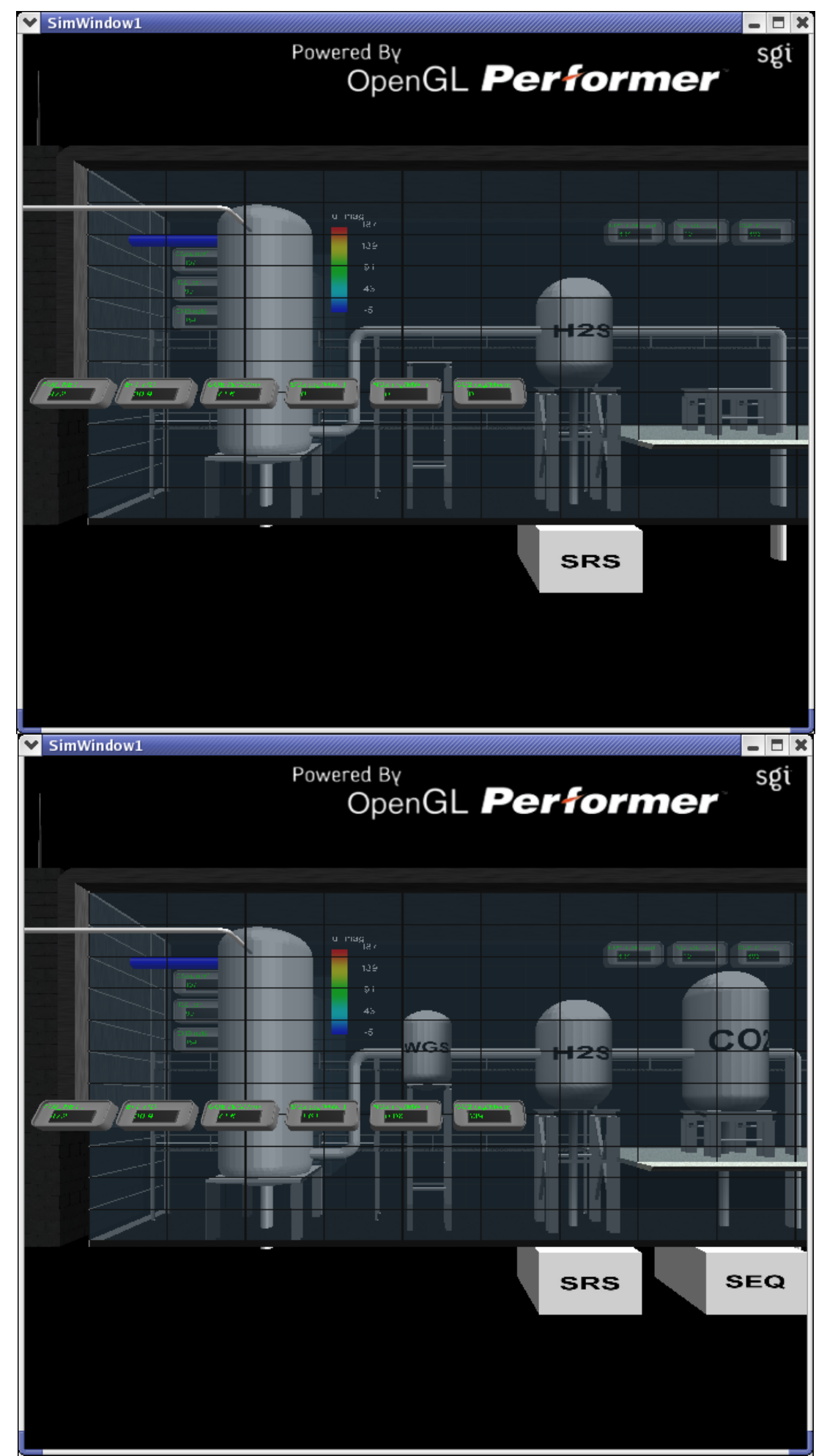

Figure 13. Virtual Reality pre-configured networks representation. 


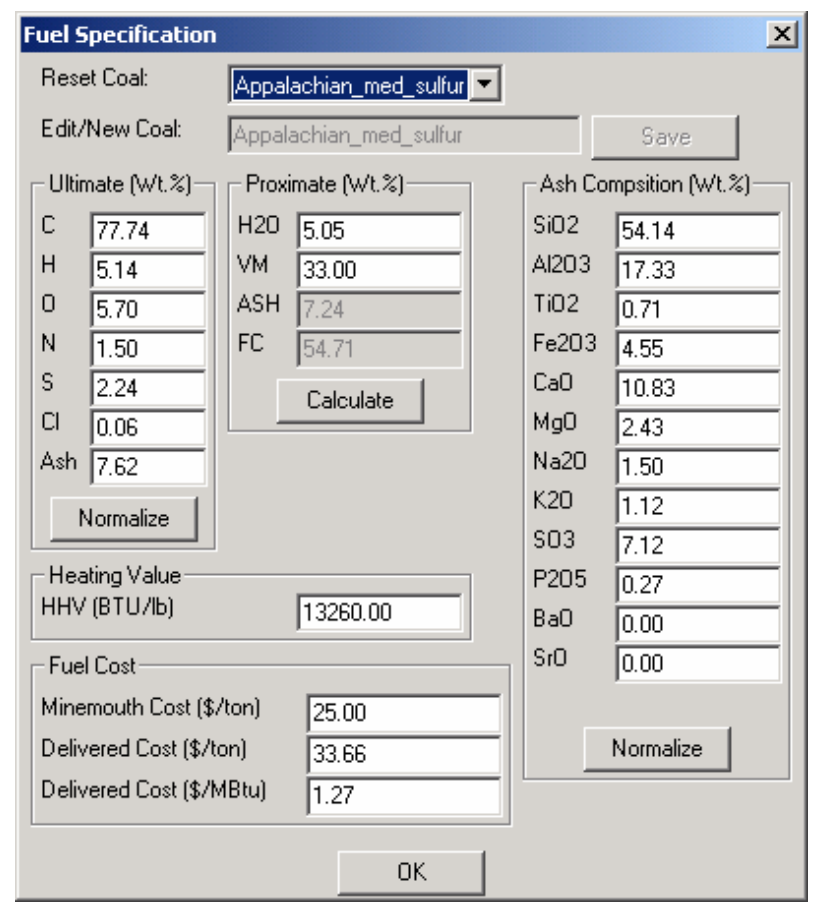

Figure 14. Sample Framework UI GUI.

\begin{tabular}{|c|c|c|c|}
\hline Result Panel & & & $x$ \\
\hline \multicolumn{4}{|l|}{ - Overall Plant- } \\
\hline Nominal Plant Output & & 601 & \multirow{3}{*}{$\begin{array}{l}(\mathrm{MW}) \\
(\mathrm{MW}) \\
(\%)\end{array}$} \\
\hline Net Electrical Output & & 472 & \\
\hline Net Plant Efficiency & & 30.9 & \\
\hline \multicolumn{4}{|l|}{ Gasifier Area- } \\
\hline Coal In & & 196.9 & \multirow{3}{*}{$\begin{array}{l}\text { (tons } / \mathrm{hr} \text { ) } \\
\text { (tons } / \mathrm{hr} \text { ) } \\
\text { (tons } / \mathrm{hr} \text { ) }\end{array}$} \\
\hline Water In & & 99.1 & \\
\hline Oxidant In & & 184.1 & \\
\hline \multicolumn{4}{|l|}{ CO2 Capture- } \\
\hline $\mathrm{CO} 2 \ln$ & & 493 & \multirow{3}{*}{$\begin{array}{l}\text { (tons } / \mathrm{hr} \text { ) } \\
\text { [tons } / \mathrm{hr} \text { ) } \\
\text { (tons } / \mathrm{hr} \text { ) }\end{array}$} \\
\hline $\mathrm{CO} 2$ Out & & 49 & \\
\hline CO2 Captured & & 444 & \\
\hline \multicolumn{4}{|l|}{ Financial Result- } \\
\hline Capital Cost & & 1910.47 & \multirow{2}{*}{$\begin{array}{l}\text { [\$/kWhet] } \\
\text { [\$/MWh] }\end{array}$} \\
\hline Electricity Cost & & 71.6 & \\
\hline & OK & Cancel & \\
\hline
\end{tabular}

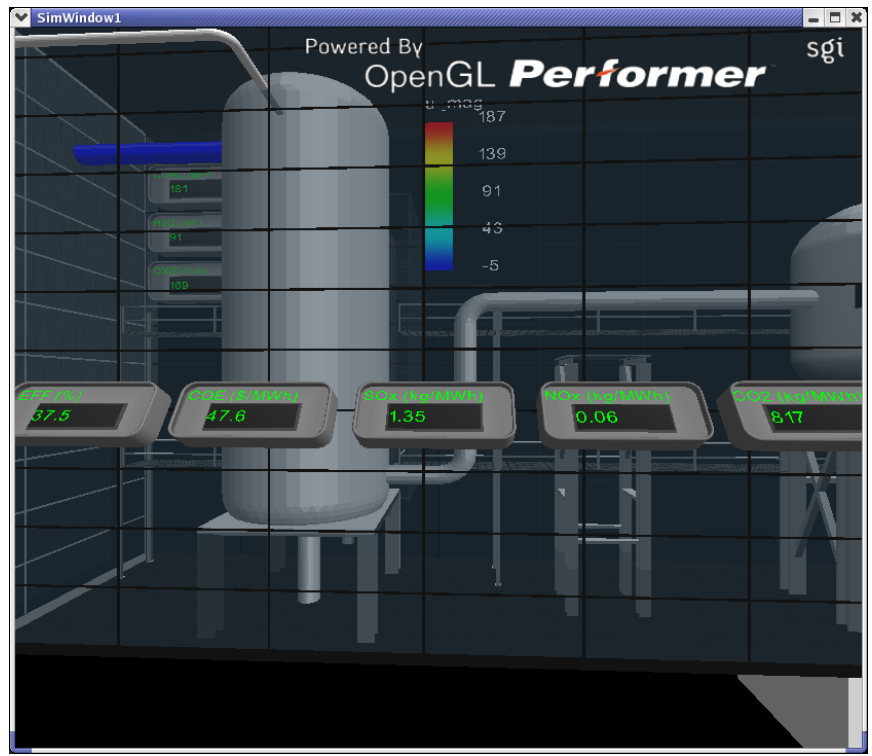

Figure 15. Framework Plant Results. 


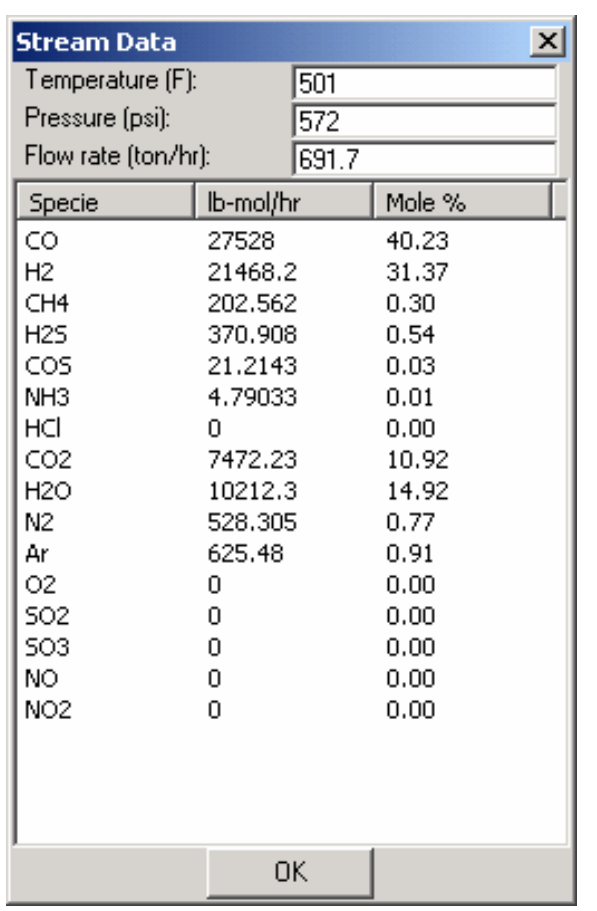

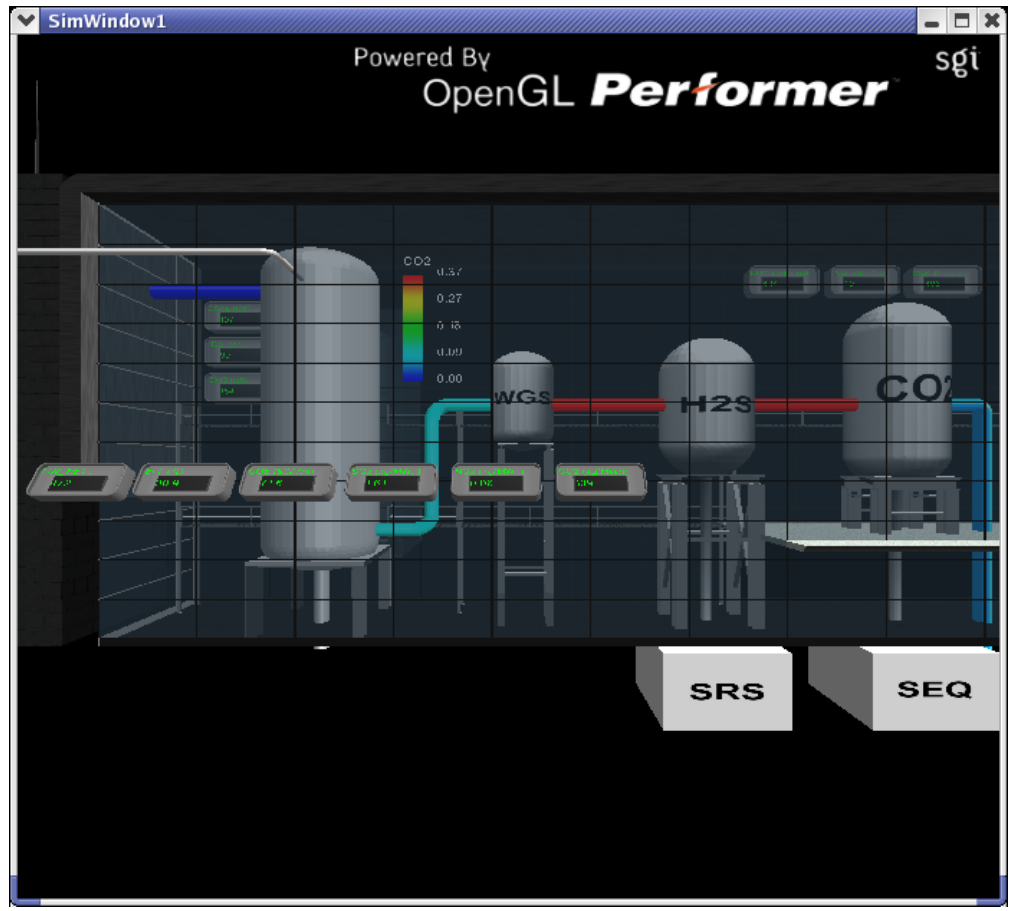

Figure 16. Framework Port Data Results. 

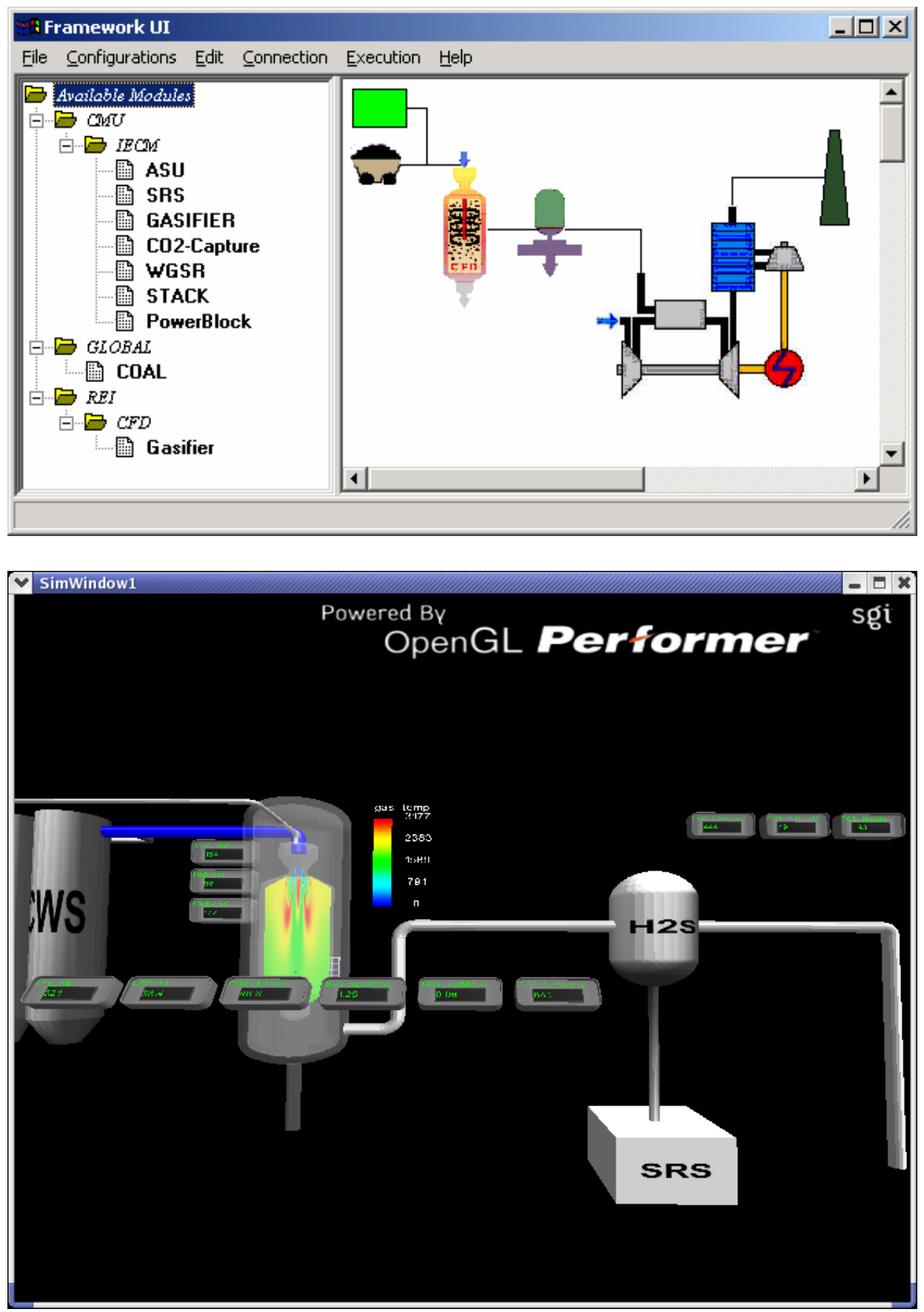

Figure 17. REI Gasifier model 


\section{Conclusions}

During the last quarter, good progress has been made on the design and development of the virtual engineering based framework.

- The coordinated effort between REI and DOE funded projects at Carnegie Mellon University and the Iowa State University Virtual Reality Applications Center continues to make significant progress. Having worked closely with one another over the past months, the teams have established effective and productive working relationships.

- The REI/CMU/ISU team has made significant progress in integrating the complex software components needed for this project. Having completed a demonstration framework, many of the initial difficult technical issues of the integration have been overcome.

- Insight into gasifier injector failure has been gained by performing detailed simulations investigating the effects of gasifier inlet conditions on the heat flux to the injector.

- Working with our collaborators at CMU and ISU, REI has created a prototype user interface for the framework. This interface provides the core functionality needed to construct and control simulations and to control the virtual engineering environment. Future enhancements will add advanced capabilities for defining looping structures, macro modules and eventually optimization.

- CMU's IECM model has been successfully integrated with the new framework. Simulation results can be displayed in the VR environment or within the user interface.

- Significant progress has been made coupling the REI computational engine with ISU's visualization engine. Although tight coupling was initially scheduled for a later date, this task has been accelerated to meet the April 19, 2004 date of the Clearwater Conference.

- Initial plans have been developed for creating models for mercury removal for advanced power generation plants for both cold and warm gas cleanup.

Plans for the next quarter include:

- Demonstrate the capabilities of the prototype framework at the International Technical Conference on Coal Utilization \& Fuel Systems in Clearwater Florida

- Enhance the level of virtual engineering functionality available with the framework through continued development of the ISU core visualization kernel (ISU task).

- Continue development of the computational engine to enhance scheduling, model integration and data passing capabilities

- Begin the process of designing advanced features for the framework user interface, including mechanisms for defining looping, macro modules, etc.

- Transfer existing REI workbench modules to the enhanced computational framework.

- Integrate improved soot and tar models into the coal gasification models. 


\section{References}

Burns, D., and Echt, W. I., "Chemical Solvent-Based Processes For Acid Gas Removal in Gasification Applications." Presented at the Gasification Technology in Practice IChemE Conference. Milan, Italy. February 1997.

Calgon Carbon Corporation, "Product Bulletin: HGR for Mercury Removal.” PB-1047-12/99.

Coulson, J. M., and Richardson, J. F., with Backhurst, J. R., and Harker, J. H., "Chemical Engineering." Volume 2, Fourth Edition, Pergamon Press, Oxford. 1991.

Eastman Chemical Company and Air Products and Chemicals, Inc, "Project Data on Eastman Chemical Company's Chemicals-from-coal Complex in Kingsport, TN." Prepared for U.S.D.O.E./N.E.T.L. under cooperative agreement No. DE-FC22-92PC90543. March 2003.

Foust, Alan Shivers, and Katz, Donald LaVerne, and Schneidewind, Richard and White, Robert Roy, and Wood, William Platt, and Brown, George Martin, and Brownell, Lloyd Earl, and Martin, Joseph J., and Williams, George Brymer, and Banchero, Julius Thomas, and York, Jesse Louis., "Unit Operations." John Wiley and Sons, Inc. New York. 1955.

Galbreath, Kevin C., and Zygarlicke, Christopher J., "Mercury Speciation in Coal Combustion and Gasification Flue Gases.” Environmental Science and Technology. Vol. 30, No. 8, 1996.

Gettert H., Jeck A. and Werner D., Process for the partial oxidation of liquid hydrocarbonaceous fuels, U.S. Patent No. 4113445, 1978.

Kohl, Arthur L., and Nielsen, Richard B., "Gas Purification.” Fifth Edition, Gulf Publishing Company, Houston, Texas. 1997.

Korens, Nick, and Simbeck, Dale R., and Wilhelm, Donald J., "Process Screening Analysis of Alternative Gas Treating and Sulfur Removal for Gasification." Prepared for U.S.D.O.E./N.E.T.L. Task Order No. 739656-00100. December 2002.

Lipp C.W., Nozzle for achieving constant mixing energy, U.S. Patent No. 4705535, 1987.

MacKenzie, Francis Chiraka Prambil, and Daniels, Christina A., and Bullin, Jeffy A., "Design and Operation of a Selective Sweetening Plant Using MDEA." Energy Progress. March 1987: 31-36.

Marion C.P. and Reynolds Blake, Synthesis gas generation, U.S. Patent No. 3705108, 1972.

McCabe, Warren L., and Smith, Julian C., and Harriott, Peter, "Unit Operations of Chemical Engineering.” Mc-Graw-Hill Book Company, New York. 1985. 
Parsons Infrastructure and Technology Group, Inc. "The Cost of Mercury Removal in an IGCC Plant.” Prepared for U.S.D.O.E./N.E.T.L.. September 2002.

Ratafia-Brown, Jay, and Manfredo, Lynn, and Hoffman, Jeffrey, and Ramezan, Massood, "Major Environmental Aspects of Gasification-Based Power Generation Technologies." Prepared for: U.S.D.O.E/N.E.T.L. Gasification Technologies Program. December 2002.

Saxon D.I., Variable capacity gasification burner, U.S. Patent No. 4502633, 1985.

Stellaccio R.J., Partial oxidation process for slurries of solid fuel, U.S. Patent No. 4443230, 1984.

Tampa Electric integrated gasification combined-cycle project, an update, Topical Report Number 19, July 2000. 


\section{1}

\section{Appendix}

\section{ABSORBER DESIGN SUMMARY}

Table A1 shows the key absorber design equations. The example illustrations that follow are based on a syngas stream having specifications given in Table A2.

Table A1. Key absorber design equations.

\begin{tabular}{|l|l|}
\hline Amine circulation rate & $\mathrm{GPM}=\frac{0.206 \cdot \mathrm{MM} \cdot\left(\mathrm{H}_{2} S+\mathrm{CO}_{2}\right) \cdot \mathrm{MolWT}}{M L \cdot W T}$ \\
\hline Absorber bubbling gas velocity & $\mathrm{U}_{\mathrm{al}}=\mathrm{K}\left(\frac{\mathbf{p}_{L}-\mathbf{p}_{G}}{\mathbf{p}_{G}^{0.5}}\right)^{0.5}$ \\
\hline Theoretical number of stages & $\mathrm{N}=\frac{\ln \left[\left(1-\mathrm{A}^{-1}\right)\left(y_{1}-y_{2}^{0}\right)\left(y_{2}-y_{2}^{0}\right)+\mathrm{A}^{-1}\right]}{\ln (\mathrm{A})}$ \\
\hline Absorption Factor & $\mathrm{A}=\frac{\mathrm{L}_{\mathrm{m}}}{\mathrm{mG}_{\mathrm{m}}}$ \\
\hline
\end{tabular}

Table A2. Syngas composition for the absorber and carbon bed.

Stream Component
$\mathrm{Ar}$
$\mathrm{C} 2 \mathrm{H} 2$
$\mathrm{C} 2 \mathrm{H} 6$
$\mathrm{CH} 4$
$\mathrm{CO}$
$\mathrm{CO} 2$
$\mathrm{COS}$
$\mathrm{H} 2$
$\mathrm{H} 2 \mathrm{O}$
$\mathrm{H} 2 \mathrm{~S}$
$\mathrm{HCl}$
$\mathrm{HCN}$
$\mathrm{N} 2$
$\mathrm{~N} 2 \mathrm{O}$
$\mathrm{NH} 3$
$\mathrm{NO}$
$\mathrm{NO} 2$

\section{$\%$ Composistion}

1.326305169

8.94349E-09

9.42013E-14

1.07934E-05

53.78752021

13.93571901

0.000330749

27.71800509

0.368373112

0.453206765

0.028186429

7.90678E-05

2.381609585

5.39106E-09

0.000508016

0.000145989

5.33932E-10 
Table A3. Syngas stream specifications

\begin{tabular}{|l|l|}
\hline Stream Property & Specification \\
\hline Gas Molecular weight & 21.65 \\
\hline Gas Density, $\mathrm{kg} / \mathrm{m}^{3}$ & 14.85 \\
\hline Gas Viscosity, $\mathrm{kg} / \mathrm{m} \mathrm{s}$ & $1.092 \times 10^{-5}$ \\
\hline Syngas flow rate, $\mathrm{kg} / \mathrm{hr}$ & 204,439 \\
\hline Temperature, $\mathrm{C}$ & 40 \\
\hline Pressure, $\mathrm{psi}$ & 250 \\
\hline Mercury inlet, $\mathrm{kg} / \mathrm{hr}$ & $7.39296 \times 10^{-3}$ \\
\hline Mercury outlet, $\mathrm{kg} / \mathrm{hr}$ & $7.39296 \times 10^{-5}$ \\
\hline
\end{tabular}

\section{Absorber design example}

(1) Amine Circulation Rate

$$
\mathrm{GPM}=\frac{0.206 \cdot \mathrm{MM} \cdot\left(\mathrm{H}_{2} \mathrm{~S}+\mathrm{CO}_{2}\right) \cdot \mathrm{MolWT}}{M L \cdot W T}
$$

$\mathrm{MM}=$ Actual gas flow rate, million cubic $\mathrm{ft} / \mathrm{day}$ $\mathrm{H}_{2} \mathrm{~S}=\mathrm{Mol} \%$ of $\mathrm{H}_{2} \mathrm{~S}$ in gas mixture to be removed $\mathrm{CO}_{2}=\mathrm{Mol} \%$ of $\mathrm{CO}_{2}$ in gas mixture to be removed MolWt $=$ Molecular weight of MDEA $=119.16$

$\mathrm{ML}=$ Mol loading, moles of acid gas $/ \mathrm{mol}$ of syngas

$\mathrm{WT}=$ Amine solution $\mathrm{wt} \%$ circulated

Actual Gas Flow Rate, MMCFD

$\mathrm{V}_{\text {flow }}=\left(\frac{56.7887}{14.8547}\right) \mathrm{m}^{3} / \mathrm{s}$

$$
\boldsymbol{\rho}=\frac{\dot{\mathrm{M}}}{\mathrm{V}} \Rightarrow \mathrm{V}_{\text {flow }}=\frac{\dot{\mathrm{M}}}{\boldsymbol{\rho}}
$$

Gas Flow rate $=3.8229 \mathrm{~m}^{3} / \mathrm{s}$

$$
\begin{aligned}
& =3.8229(60)(60)(24) \mathrm{m}^{3} / \text { day } \\
& =3.8229(60)(60)(24)(3.2808)^{3} \mathrm{CF} / \mathrm{D} \\
& =11,663,3958 \\
\mathrm{MM} & =11.6 \text { MMCFD }
\end{aligned}
$$

Moles of $\mathrm{H}_{2} \underline{\mathrm{S}}$ to be removed

$\mathrm{H}_{2} \mathrm{~S}=\% \mathrm{H}_{2} \mathrm{~S}$ in syngas $=0.45 \%$

$\mathrm{CO}_{2}=1 / 2\left(\% \mathrm{CO}_{2}\right)$ in syngas $=14 / 2=7 \%$ 


\section{$\underline{\text { Molecular Wt of MDEA }}$}

$\mathrm{MDEA}=119.16$

Mole Loading [Note: Water in syngas is $0.5 \%$ ]

Moles of syngas $\left.=\left(\frac{56.7887}{21.16}\right) \frac{\mathrm{kg}}{\mathrm{s}}\right) \frac{1}{\mathrm{~kg} / \mathrm{kgmol}}$

Moles of $\mathrm{H}_{2} \mathrm{~S}=\left(\right.$ mol fraction $\left.\mathrm{H}_{2} \mathrm{~S}\right)$ (moles of syngas)

$$
=(0.00346630)(2.6837)
$$

Moles of $\mathrm{H}_{2} \mathrm{~S}=0.00898127 \mathrm{kgmol} / \mathrm{s}$

Moles of $\mathrm{CO}_{2}=\left(\mathrm{mol}\right.$ fraction $\left.\mathrm{CO}_{2}\right)($ moles of syngas $)$

$$
=(0.102900)(2.6837)=0.2698 \mathrm{kgmol} / \mathrm{s}
$$

Moles of acid gas $=\mathrm{Mol} \mathrm{H} 2 \mathrm{~S}+\mathrm{Mol} \mathrm{CO} 2$

$$
=.2785 \mathrm{kgmol} / \mathrm{s}
$$

$\mathrm{ML}=\frac{\text { molesof acidgas }}{\text { molesof syngas }}=\frac{0.2785}{0.26837}=0.104$

Amine Solution $\mathrm{Wt} \%$ Circulated (Assumed)

Assume 50\%

$$
\begin{aligned}
& \mathrm{WT}=50 \\
& \mathrm{GPM}=\frac{(0.206)(11.6)(0.45+7.0)(119.16)}{(0.104)(50)} \\
& \mathrm{GPM}=403
\end{aligned}
$$

(2) Bubbling Area (Active Area)

$$
\mathrm{U}_{\mathrm{al}}=\mathrm{K}\left(\frac{\mathbf{p}_{L}-\boldsymbol{p}_{G}}{\boldsymbol{\rho}_{G}^{0.5}}\right)^{0.5}
$$

where $\mathrm{K}=0.25$ for valve trays, 0.20 for bubble cap trays

$\mathrm{U}_{\mathrm{al}}=$ Allowable velocity of gas through bubbling area, $\mathrm{ft} / \mathrm{s}$

$\rho_{\mathrm{L}}=$ Density of amine solution, $\mathrm{lb} / \mathrm{ft}^{3}$

$\rho_{\mathrm{G}}=$ Density of syngas at tray conditions, $\mathrm{lb} / \mathrm{ft}^{3}$ 


$$
\mathrm{U}_{\mathrm{al}}=0.25\left(\frac{64.4-0.93}{0.93^{0.5}}\right)^{0.5}=2.0281661 \mathrm{ft} / \mathrm{s}
$$

$\begin{aligned} \text { Actual volumetric flow of Syngas } & =\frac{\dot{\mathbf{M}}}{\boldsymbol{\rho}}=\left(\frac{56.7887}{14.8547}\right)=3.8229 \mathrm{~m}^{3} / \mathrm{s} \\ & =3.8229(35.31) \mathrm{ft}^{3} / \mathrm{s} \\ & =135 \mathrm{ft}^{3} / \mathrm{s}\end{aligned}$

Bubbling Area $=\frac{135}{2.0281661}=66.6 \mathrm{ft}^{2}$

Area of downcomer

Assume a down flow velocity of $0.25 \mathrm{ft} / \mathrm{s}$

$$
\begin{aligned}
\text { Downcomer area }=\frac{\text { AmineFlow rate }}{\text { Flow velocity }} & =\left(\frac{403 \cdot 1}{60 \cdot 7.48}\right) \frac{\mathrm{ft}^{3} / \mathrm{s}}{0.25} \\
& =3.6 \mathrm{ft}^{3} / \mathrm{s}
\end{aligned}
$$

Note: $7.48 \mathrm{gal}=1 \mathrm{ft}^{3}$

Total required Tray Area $=(66.6+3.6+3.6)(1.15)$

$$
=84.87 \mathrm{ft}^{2}
$$

$\underline{\text { Tray Diameter }}$

$$
\begin{aligned}
& A=\frac{D^{2}}{4} \\
& D=\sqrt{\frac{4 A}{\pi}}
\end{aligned}
$$

$\mathrm{D}=\sqrt{\frac{4 A}{\boldsymbol{\pi}}}=\sqrt{\frac{4 \cdot 84.87}{\boldsymbol{\pi}}}=10.4 \mathrm{ft}$

Select D $=10 \mathrm{ft}$

$\underline{\text { Clear Liquid Residence Time }}$

$$
\text { CLRT }=\frac{(\text { BubblingArea })(\text { Froh Depth })}{\text { LiquidFlow Rate }} \cdot \text { Frothgravity }
$$




$$
=\frac{(66.6)\left(\frac{3.1}{12}\right)(0.3)}{(7.48)(60)}=5.7 \mathrm{~s}
$$

(Standard residence time 2 seconds)

\section{THEORETICAL NUMBER OF STAGES}

Colburn (1939) (See Perry, Seventh Edition Chapter 14)

Number of Stages, $\mathrm{N}$

$$
\mathrm{N}=\frac{\ln \left[\left(1-\mathrm{A}^{-1}\right)\left(y_{1}-y_{2}^{0}\right)\left(y_{2}-y_{2}^{0}\right)+\mathrm{A}^{-1}\right]}{\ln (\mathrm{A})}
$$

where $\mathrm{A}=\mathrm{L}_{\mathrm{m}} / \mathrm{mG}_{\mathrm{m}}$, the Absorption factor

$\mathrm{L}_{\mathrm{m}}=$ liquid molar flow rate/unit area (i.e. solvent entering at the top of tower)

$\mathrm{G}_{\mathrm{m}}=$ Gas molar flow rate/unit area (i.e. syngas entering at bottom of tower)

$\mathrm{m}=$ slope of equilibrium curve

Note: This analysis is valid only if the equilibrium curve is represented by $\mathrm{y}_{\mathrm{e}}=\mathrm{mx}$

Liquid Flow rate at tower entrance (top)

$\mathrm{kg} / \mathrm{m}^{3}$

MolWt $=119.16$

Volumetric flow rate of MDEA

$$
\begin{aligned}
\mathrm{L}_{\mathrm{m}} & =403 \mathrm{gpm} \\
& =\left(\frac{403}{7.48}\right) \mathrm{ft}^{3} / \mathrm{min} \\
& =\left(\frac{403}{7.48 \cdot 60}\right) \cdot(0.3048)^{3} \mathrm{~m}^{3} / \mathrm{s} \\
& =0.0254266 \mathrm{~m}^{3} / \mathrm{s}
\end{aligned}
$$

Mass Flow of MDEA/ Molar Flow Rate

$$
\dot{\mathrm{m}}_{\text {MDEA }}=(1041)(0.0254266) \mathrm{kg} / \mathrm{s}
$$




\section{6}

Molar Flow Rate MDEA $=\frac{(1041)(0.0254266)}{119.16} \mathrm{kgmol} / \mathrm{s}$

$$
=0.2221 \mathrm{kgmol} / \mathrm{s}
$$

Tray area $=84.87 \mathrm{ft}^{2}=7.88 \mathrm{~m}^{2}$

$$
\mathrm{L}_{\mathrm{m}}=\frac{0.2221}{7.88}=\frac{\mathrm{kgmol}}{\mathrm{m}^{2} \cdot \mathrm{s}}=0.0281685 \frac{\mathrm{kgmol}}{\mathrm{m}^{2} \cdot \mathrm{s}}
$$

Syngas Flow Rate $\mathrm{G}_{\underline{m}}$ per tray area

$$
\begin{aligned}
\dot{\mathrm{m}}_{\text {syngas }} & =56.7887 \mathrm{~kg} / \mathrm{s} \\
& =\left(\frac{56.7887}{21.65}\right) \mathrm{kgmol} / \mathrm{s}
\end{aligned}
$$

$\mathrm{G}_{\mathrm{m}}=\left(\frac{56.7887}{21.65 \cdot 7.88}\right) \frac{\mathrm{kgmol}}{\mathrm{m}^{2} \cdot \mathrm{s}}$

$\mathrm{G}_{\mathrm{m}}=0.332872 \frac{\mathrm{kgmol}}{\mathrm{m}^{2} \cdot \mathrm{s}}$

$\underline{\text { Slope of equilibrium curve }}$

For $50 \%$ MDEA, at $40^{\circ} \mathrm{C}$, the slope of the equilibrium curve, $\mathrm{m}=0.0304$

$\underline{\text { Absorption factor }}$

$$
\mathrm{A}=\frac{\mathrm{L}_{\mathrm{m}}}{\mathrm{mG}_{\mathrm{m}}}
$$

$\mathrm{A}=\frac{0.0254266}{(0.0304)(0.332872)}=2.5$

Mole fraction $\mathrm{H}_{2} \underline{\mathrm{S} \text { in the entering syngas }}$

$\mathrm{y}_{1}=0.0033466$ [from the composition of syngas]

Mole fraction of $\mathrm{H}_{2} \underline{\mathrm{S}}$ in the syngas leaving the Absorber

Specify $1 \mathrm{ppm} \mathrm{H}_{2} \mathrm{~S}$ in syngas for fuel cell use. 
To reach this level, the inlet syngas must have $99.97 \% \mathrm{H}_{2} \mathrm{~S}$ removal.

Using the Example data,

$\mathrm{y}_{2}=0.00000100398$

Also $\mathrm{y}_{2}^{0}=0$ [mole fraction of $\mathrm{H}_{2} \mathrm{~S}$ in fresh amine]

$\underline{\text { Theoretical Number of Trays }}$

$\mathrm{N}=\frac{\ln \left[\left(1-\frac{1}{2.5}\right)(0.0033466)(0.0000010038)+\frac{1}{2.5}\right]}{\ln (2.5)}$

$\mathrm{N}=8.3$

Actual Number of trays $=3 \quad 8.3 \quad 24.5$

Select 25 trays

Absorber height $=25 \times 2=50 \mathrm{ft}$ tall

[Note: Each tray is separated from the other by $2 \mathrm{ft}$ ].

\section{$\underline{\text { CARBON BED DESIGN SUMMARY }}$}

Table A4. Key carbon bed design equations.

\begin{tabular}{|l|l|}
\hline $\begin{array}{l}\text { Carbon bed minimum fluidization } \\
\text { velocity }\end{array}$ & $U_{m f}=\operatorname{Re}_{m f}\left(\frac{\mu}{d \rho}\right)$ \\
\hline $\begin{array}{l}\text { Reynolds Number at minimum } \\
\text { fluidization }\end{array}$ & $\operatorname{Re}_{m f}=25.7(\sqrt{1+(5.53 E-5) G a}-1\}$ \\
\hline Galileo Number & $G a=\frac{d^{3} \boldsymbol{p}\left(\boldsymbol{\rho}_{s}-\boldsymbol{\rho}\right) g}{\boldsymbol{\mu}^{2}}$ \\
\hline Ergun's Pressure Drop Equation & $\frac{\Delta P}{L}=\frac{150(1-e)^{2}}{e^{3}} \frac{\boldsymbol{\mu}_{0}}{d^{2}}+1.75 \frac{(1-e)}{e^{3}} \mathbf{p} \frac{U_{0}^{2}}{d}$ \\
\hline
\end{tabular}

\section{Carbon Bed Design Example}


(0) Allowable pressure drop ( $0.26 \mathrm{psi} / \mathrm{ft})$ depends on carbon bulk density.

(1) Determine the minimum fluidization velocity at the prevailing conditions

$$
\begin{gathered}
U_{m f}=\operatorname{Re}_{m f}\left(\frac{\mu}{d \rho}\right) \\
\operatorname{Re}_{m f}=25.7\{\sqrt{1+(5.53 E-5) G a}-1\} \\
G a=\frac{d^{3} \mathbf{p}\left(\mathbf{p}_{s}-\mathbf{p}\right) g}{\boldsymbol{\mu}^{2}}
\end{gathered}
$$

Operating Conditions:

$\mathrm{T}=313 \mathrm{~K}=100^{\circ} \mathrm{F}$

$P=255 \mathrm{psi}$

$\mu=1.092 \mathrm{E}-5 \mathrm{~kg} / \mathrm{ms}$

$\rho_{\mathrm{s}}=592.7 \mathrm{~kg} / \mathrm{m}^{3}$

$\rho=14.85 \mathrm{~kg} / \mathrm{m}^{3}$

$d=3.38 \mathrm{E}-3 \mathrm{~m}[4 \times 10$ mesh granules $]$

$\therefore G a=\frac{(3.38 E-3)^{3} \cdot 14.85(592.7-14.85) \cdot 9.81}{(1.092 E-5)^{2}}$

$G a=2.725 E 7$

$\operatorname{Re}_{m f}=972.5$

$\mathrm{U}_{m f}=0.2116 \mathrm{~m} / \mathrm{s} \quad[41.4 \mathrm{ft} / \mathrm{min}]$

Select Value of $U_{0}$ depending on accuracy of the $U_{m f}$ correlation. For design use the lower end of the value - may even have to use $50-80 \%$ of the lower value. Compare the selected $U_{0}$ with the practical experience $U_{0}$ values.

(2) Calculate $\frac{P}{L}$ for $U_{m f}$ using Ergun's equation.

$$
\frac{\Delta P}{L}=\frac{150(1-e)^{2}}{e^{3}} \frac{\boldsymbol{\mu U}_{0}}{d^{2}}+1.75 \frac{(1-e)}{e^{3}} \mathbf{p} \frac{U_{0}^{2}}{d}
$$

for a bed of Char e $\quad 0.7$ (Kunii and Levenspiel (1969))

$U_{0}=0.2116 \mathrm{~m} / \mathrm{s}$ 
$\therefore \frac{\Delta P}{L}=308.5 \mathrm{~Pa} / \mathrm{m}$

$$
=\frac{308.5 \cdot 14.7}{1000 \cdot 101.3 \cdot 0.3048} \mathrm{psi} /(\mathrm{ft} \text { of bed })
$$

$\frac{\Delta}{L}=0.1469 \mathrm{psi} /(\mathrm{ft}$ of bed $)(0.26 \mathrm{psi} / \mathrm{ft})$

Calgon chart for a bed at 300 psi gives $\frac{\Delta P}{L}=0.1626$ at $35 \mathrm{ft} / \mathrm{min}$

(3) Specify $U_{0}$

$U_{0}=0.85 U_{m f}=35 \mathrm{ft} / \mathrm{min}=0.1778 \mathrm{~m} / \mathrm{s}$

Calgon-Carbon Experience specifies 35-50 ft/min

(4) Check $\frac{P}{L}$ using Calgon-Carbon Charts for $U_{0}$

Using charts for $300 \mathrm{psi}$ and $35 \mathrm{ft} / \mathrm{min}$

$$
\frac{\Delta}{L}=0.1626 \mathrm{psi} / \mathrm{ft}
$$

This is below the allowable pressure drop of $0.26 \mathrm{psi} / \mathrm{ft}$

(5) Specify Residence time

This value comes from operating experience. Calgon-Carbon/ Eastman recommend $\tau=20 \mathrm{~s}$

(6) Determine Initial Carbon Bed Height

Bed Height, $\mathrm{H}=$

$$
\begin{aligned}
\mathrm{H} & =U_{0} \tau \\
& =(0.1778)(20) \\
\mathrm{H} & =3.556 \mathrm{~m}(11.7 \mathrm{ft})
\end{aligned}
$$

(7) Determine Mass of Carbon Needed 


\section{0}

Note $\mathrm{Q}=$ Volumetric flow rate $\left(\mathrm{m}^{3} / \mathrm{s}\right)$

$$
\begin{gathered}
\text { Mass }=\rho \mathrm{V}=\rho \mathrm{AH} \\
\mathrm{A}=\frac{\mathrm{Q}}{U_{0}}=\left(\frac{\dot{\mathrm{M}}_{\text {syngas }}}{\rho_{\text {syngas }}}\right) \frac{1}{U_{0}}
\end{gathered}
$$

$$
\begin{aligned}
A & =\left(\frac{56.7887}{14.8547}\right) \frac{1}{0.1778} \\
A & =21.5 \mathrm{~m}^{2}
\end{aligned}
$$

Mass of Carbon $=\rho H A=(592.7)(21.5)(3.556) \mathrm{kg}$

$$
=45,314 \mathrm{~kg}
$$

(Note: a higher value of $U_{0}$ will give a lower value of Carbon weight).

(8) Adsorber diameter

$$
\begin{aligned}
& \mathrm{A}=\frac{\mathrm{D}^{2}}{4} \\
& \mathrm{D}=\sqrt{\frac{4 A}{\pi}}
\end{aligned}
$$

$D=\sqrt{\frac{4 \cdot 21.5}{\boldsymbol{\pi}}}=2.334 \mathrm{~m}(17.2 \mathrm{ft})$

Specify $\mathrm{D}=6 \mathrm{~m}$, use 2 vessels of $3 \mathrm{~m}$ diameter each.

To allow for free space above and below the bed, make $\mathrm{H}=4 \mathrm{~m}$

(9) Bed Pressure drop

psi

P. 3 psi

(10) Mercury Removal

Coal feed rate: $(35.84) \frac{64.5}{100} \mathrm{~kg} / \mathrm{s}$ (wet coal)

Coal moisture $=11.12 \%$ 


\section{1}

Dry Coal feed rate $=\frac{(35.814)(64.5)}{100} \cdot \frac{88.88}{100}$

$$
=20.531 \mathrm{~kg} / \mathrm{s}
$$

Mercury in Illinois No. 6 Coal $=0.1 \mu \mathrm{g} / \mathrm{g}$ d.b. $(100 \mu \mathrm{g} / \mathrm{kg}$ d.b. $)$

Mercury feed rate $=(20.531)(100) \mu \mathrm{g} / \mathrm{s}$

Assume that all Mercury leaving the gasifier enters the carbon bed.

Also assume that the bed will be operated for 2 years before replacing the carbon.

Assuming 99\% removal, Hg captured by the bed in 2 years

$\mathrm{Hg}$ feed $=2.053 \mathrm{E}-6(60)(60)(24)(365)(2) \mathrm{kg}$

$$
=129.5 \mathrm{~kg}
$$

Hg Removal $=(0.99)(129.5)=128.2 \mathrm{~kg}$

Carbon Loading $=\frac{128.2}{45,000}=0.28 \%$ 